\title{
Numerical simulation of kinetic demixing and decomposition in a LaCoO3- oxygen membrane under an oxygen potential gradient
}

Ta, Na; Chen, Ming; Zhang, Lijun ; Chatzichristodoulou, Christodoulos; Chen, Weimin ; Hendriksen, Peter Vang; Du, Yong

Published in:

Journal of Membrane Science

Link to article, DOI:

10.1016/j.memsci.2017.11.033

Publication date:

2018

Document Version

Peer reviewed version

Link back to DTU Orbit

Citation $(A P A)$ :

Ta, N., Chen, M., Zhang, L., Chatzichristodoulou, C., Chen, W., Hendriksen, P. V., \& Du, Y. (2018). Numerical simulation of kinetic demixing and decomposition in $\mathrm{LaCoO}_{3}$ oxygen membrane under an oxygen potential gradient. Journal of Membrane Science, 548, 526-539. https:/3doi.org/10.1016/j.memsci.2017.11.033

\section{General rights}

Copyright and moral rights for the publications made accessible in the public portal are retained by the authors and/or other copyright owners and it is a condition of accessing publications that users recognise and abide by the legal requirements associated with these rights.

- Users may download and print one copy of any publication from the public portal for the purpose of private study or research.

- You may not further distribute the material or use it for any profit-making activity or commercial gain

- You may freely distribute the URL identifying the publication in the public portal 
1 Numerical simulation of kinetic demixing and decomposition in a $\mathrm{LaCoO}_{3-\delta}$

\title{
oxygen membrane under an oxygen potential gradient
}

\author{
Na Ta ${ }^{\mathrm{a}, \mathrm{b}}$, Ming Chen ${ }^{\mathrm{b}}$, Lijun Zhang ${ }^{\mathrm{a}}{ }^{*}$, Christodoulos Chatzichristodoulou ${ }^{\mathrm{b}}$, Weimin Chen $^{\mathrm{a}}$, Peter \\ Vang Hendriksen ${ }^{\mathrm{b}}$, Yong $\mathrm{Du}^{\mathrm{a}}$ \\ a State Key Laboratory of Powder Metallurgy, Central South University, Changsha, Hunan 410083, China \\ ${ }^{\mathrm{b}}$ Department of Energy Conversion and Storage, Technical University of Denmark, Roskilde 4000, Denmark \\ Corresponding author: Ming Chen \\ Tel.: + 467757 57; Fax: + 46775858 . \\ E-mail address: minc@dtu.dk (Ming Chen) \\ Corresponding author: Lijun Zhang \\ Tel.: +86 731 88877963; Fax: +86 7318710855 . \\ E-mail address: lijun.zhang@,csu.edu.cn (Lijun Zhang) \\ Other authors: \\ Na Ta: E-mail address: tagetacpu@163.com; \\ Christodoulos Chatzichristodoulou: E-mail address: ccha@dtu.dk \\ Weimin Chen: E-mail address: chenweiming126@163.com \\ Peter Vang Hendriksen: E-mail address: pvhe@dtu.dk \\ Yong Du: E-mail address: yong-du@,mail.csu.edu.cn
}

\begin{abstract}
A composition- and temperature-dependent mobility database of all ionic species in the $\mathrm{LaCoO}_{3-\delta}$ phase was developed and combined with a La-Co-O thermodynamic database to simulate kinetic demixing and partial decomposition in $\mathrm{LaCoO}_{3-\delta}$ oxygen membranes operated under a 0.0001/0.21 bar oxygen partial pressure difference at $1073 \mathrm{~K}$ for 1 year. Formation of $\mathrm{La}_{2} \mathrm{O}_{3}, \mathrm{Co}_{3} \mathrm{O}_{4}$ and $\mathrm{CoO}$ phases across the membrane is predicted. The kinetic demixing process can be divided into two stages, namely, establishment of the oxygen potential gradient (fast) and demixing of the cations (slow); the former is controlled by the mobility of oxygen ions, and the latter is determined by the higher mobility of $\mathrm{Co}$ ions as compared to the La ion in the $\mathrm{ABO}_{3}$-type perovskite. A drift motion of both oxide surfaces towards the high $\mathrm{PO}_{2}$ side occurs with the movement of cations.

Keywords: $\mathrm{LaCoO}_{3-\boldsymbol{\delta}}$, Kinetic demixing/decomposition, Oxygen potential gradient, Oxygen membrane

\section{Introduction}

Owning to ability to maintain high oxygen flux and long-term stability at high temperatures of $800 \sim 1000^{\circ} \mathrm{C}$, mixed ionic and electronic conducting (MIEC) perovskite-type $\mathrm{A}_{\mathrm{x}} \mathrm{A}^{\prime}{ }_{1-\mathrm{x}} \mathrm{B}_{\mathrm{x}} \mathrm{B}^{\prime}{ }_{1-\mathrm{x}} \mathrm{O}_{3-\delta}$ oxides are widely studied for oxygen-permeable membranes. Among these oxides, the Sr and/or Fe-doped multi-component $\mathrm{LaCoO}_{3-\delta}$ perovskite-type oxide is a preferred system due to a good compromise of properties. During the service in a $\mathrm{PO}_{2}$ gradient, kinetic demixing of the cations/anions, and even kinetic decomposition (i.e., formation of new phases) may occur in the original homogeneous oxide matrix, resulting in inevitable degradation of the membrane.

There are only few of experimental work on the demixing and/or decomposition behavior of $\mathrm{Sr}$ and/or Fe-doped $\mathrm{LaCoO}_{3-\delta}$ perovskite-type oxides available in the literature. Schlehuber et al. [1]
\end{abstract}


observed different oxide layers on the feed and the permeate surfaces of $\mathrm{La} 0.58 \mathrm{Sr} 0.4 \mathrm{Co} 0.2 \mathrm{Fe} 0.8 \mathrm{O}_{3-\delta}$ membranes at $800^{\circ} \mathrm{C}$ after $3000 \mathrm{~h}$. Van Doorn et al. [2] found strontium enrichment at the low oxygen partial pressure side of $\mathrm{La} 0.3 \mathrm{Sr}_{0.7} \mathrm{CoO}_{3-\delta}$ membranes after long-term oxygen permeation. Moreover, Lein et al. [3] confirmed the kinetic decomposition and demixing in a La0.3 $\mathrm{Sr}_{0.7} \mathrm{Co}_{1-\mathrm{x}} \mathrm{Fe}_{\mathrm{X}} \mathrm{O}_{3-\delta} \delta$ membrane observing cobalt oxide on the oxidizing side at $1423 \mathrm{~K}$. Wang et al. $[4,5]$ reported that the kinetic demixing and the decomposition rates of $\mathrm{La}_{0.6 \mathrm{Sr}} \mathrm{S}_{4} \mathrm{Co} 0.2 \mathrm{Fe} 0.8 \mathrm{O}$ 3- $\delta$ membranes were self-accelerating with time at the air-side surface.

However, long-term performance measurements are hard to achieve experimentally. Theoretical modeling may serve as an important supplement for studying kinetic demixing and decomposition phenomena during the long service lifetime of oxygen membranes. Up to now, some reports on theoretical modeling of the demixing and even decomposition phenomena in solid ionic compounds are available in the literature. Martin et al. [6,7] studied the demixing phenomenon in semi-conducting oxide solid solution $(\mathrm{A}, \mathrm{B})_{1-\delta} \mathrm{O}$ and $\mathrm{A}_{1-\delta} \mathrm{O}$ under an oxygen potential gradient in the steady state. By means of a finite difference method, Hong et al. [8] described the transient demixing process in the oxide $(\mathrm{A}, \mathrm{B})_{1-\delta} \mathrm{O}$. Sato et al. [9] employed the statistical mechanical method to investigate the demixing of solid solutions, which was later extended by Ishikawa et al. [10] to simulate the time evolution of the demixing profiles. Though the above-mentioned modeling approaches can reasonably describe the demixing phenomenon in $(A, B){ }_{1-\delta} \mathrm{O}$ oxides, the oxygen ions were assumed to be immobile and only the kinetic demixing in a single phase was investigated in those approaches [6-10]. Recently, Chatzichristodoulou et al. [11] determined the steady state demixing profile in the $8 \mathrm{YSZ}$ ( $\left.\mathrm{Zr}_{0.85} \mathrm{Y}_{0.15} \mathrm{O}_{1.925}\right)$ oxide ion conducting electrolyte of a solid oxide electrolysis cell (SOEC) under polarization. For the decomposition phenomenon, the only report is from Schmalzried et al. [12], who addressed the kinetic decomposition in the steady state by using a phenomenological method. However, neither a real thermodynamic database nor a kinetic (i.e. diffusion mobility) database was used, and thus no quantitative description could be obtained. In addition, one more disadvantage in the reported modeling approaches lies in that all the compounds were described as ideal solutions (i.e. $(\mathrm{A}, \mathrm{B})_{1-\delta} \mathrm{O}$ was treated as an ideal solution of $\mathrm{AO}$ and $\mathrm{BO}$ ); as a result, the atomistic features of the process cannot be identified, i.e., the energy construction is based on the mixture of compounds $\mathrm{AO}$ and $\mathrm{BO}$ rather than the specific crystal structure.

So far, no effort has been made to model the demixing and even decomposition behavior in MIEC perovskite-type oxides. Thus, there is need to remedy this situation. Moreover, this type of modeling is also of relevance in the SOFC cathodes under strong polarization [13-15]. In recent years, the DIffusion-Controlled TRAnsformation (DICTRA) software package, which operates under the CALculation of PHAse Diagram (CALPHAD) framework and on the hypothesis of sharp interface and local equilibrium (i.e. the interface thickness is considered zero in the sharp interface assumption, and local chemical potential is considered identical across the interface), has been developed, and successfully applied to simulate various diffusion-controlled phase transformation processes in different materials [16-20]. One of the key points for a quantitative DICTRA simulation is reliable thermodynamic and atomic mobility databases. DICTRA simulations are both time- and space-dependent, but limited to be one-dimensional (1-D), providing a possibility for efficient numerical simulations during long-term services. Very recently, DICTRA has been employed to establish an atomic mobility database for oxides [16,21], based on which the oxidation processes on pure $\mathrm{Cr}$ and $\mathrm{Fe}$ were nicely simulated [16].

Consequently, the major objective of the present work is to perform a quantitative description of the kinetic demixing and decomposition process in $\mathrm{LaCoO}_{3-\delta}$ oxygen membranes under an oxygen potential gradient during long-term service lifetime (i.e., almost 1 year) by using 1-D DICTRA 
simulation with tubular geometry, from which the effect of kinetic demixing and decomposition process of the membrane can be analyzed. In order to achieve a quantitative description, the composition and temperature-dependent diffusion mobilities database of $\mathrm{LaCoO}_{3-\delta}$ system was first established on the basis of available literature data together with the existing CALPHAD thermodynamic database [22]. Table 1 is a list of symbols used in the text.

Table 1

Nomenclature

\begin{tabular}{|c|c|c|c|}
\hline$T$ & Absolute temperature, $\mathrm{K}$ & $y_{i}^{j}$ & Site fraction of $i$ in the $j_{t h}$ site \\
\hline$R$ & Gas constant, $8.31451 \mathrm{~J} \mathrm{~mol}^{-1} \mathrm{~K}^{-1}$ & $\eta_{i}$ & Electrochemical potential of component $i$ \\
\hline$y_{i}$ & Site fraction of constituent $i$ & $\varphi$ & Electrical potential \\
\hline${ }^{0} G_{i: j: k}^{\theta}$ & $\begin{array}{l}\text { Gibbs energy of the end-member component } \\
\qquad(i)_{1}(j)_{1}(k)_{3}\end{array}$ & $z_{i}$ & Charge of species $i$ \\
\hline${ }^{E} G_{m}^{\theta}$ & $\begin{array}{l}\text { Excess Gibbs energy of phase } \theta \text { per mole } \\
\text { component. The excess Gibbs energy accounts for } \\
\text { contributions due to non-ideal interaction between } \\
\text { the components. }\end{array}$ & $F$ & Faraday's constant, $96485.3 \mathrm{C} \mathrm{mol}^{-1}$ \\
\hline$\mu_{i}$ & Chemical potential of component $i$ & $M_{i}^{*}$ & Diffusion mobility of the component $i$ \\
\hline$G_{m}^{\gamma}$ & Mole Gibbs free energy of phase $\gamma$ & $L_{i i}$ & Onsager coefficient \\
\hline$x_{i}$ & Mole fraction of component $i$ & $V_{m}$ & Molar volume of the phase, $\mathrm{cm}^{3} \mathrm{~mol}^{-1}$ \\
\hline$M_{i}^{j}$ & Mobility of the component $i$ in the $j_{t h}$ site & $M_{i V a}^{j}$ & Kinetic parameter of the component $i$ in the $j_{t h}$ site \\
\hline$Q$ & Diffusion activation energy, $\mathrm{kJ} \mathrm{mol}^{-1}$ & $D_{i j}$ & Chemical diffusion coefficients, $\mathrm{m}^{2} \mathrm{~s}^{-1}$ \\
\hline$\vec{J}_{i}^{\theta}$ & $\begin{array}{l}\text { Chemical diffusion flux of component } i \text { in phase } \theta \\
\text { ( } \theta \text { is usually omitted })\end{array}$ & $\mu_{k}^{l . e q}$ & $\begin{array}{l}\text { Local chemical potential corresponding to the local } \\
\text { equilibrium in Gibbs energy }\end{array}$ \\
\hline$M_{k}^{e f f}$ & Local effective mobility of species $k$ & $x_{k}^{1}\left(x_{k}^{2}\right)$ & $\begin{array}{l}\text { Local overall mole fractions of species } k \text { on } \\
\text { plane/source } 1 \text { and } 2\end{array}$ \\
\hline$\Delta \widetilde{z}$ & Grid spacing for simulation, $\mathrm{m}$ & $f^{\alpha}$ & Volume fraction of phase $\alpha$ \\
\hline$\vec{I}_{i}$ & Electric current density of component $i$ & $\sigma_{i o n}$ & Ionic conductivity \\
\hline$\sigma_{e}$ & Electron conductivity & $x_{i}^{\theta}$ & Mole fraction of component $i$ in phase $\theta$ \\
\hline$\vec{v}_{P h 1 / P h 2}$ & $\begin{array}{l}\text { The interface velocity between Phase1 and Phase 2, } \\
\qquad \mathrm{m} \mathrm{s}^{-1}\end{array}$ & $C_{i}$ & Concentration of component $i$ \\
\hline$P$ & Pressure, bar & $\vec{J}_{i^{*}}$ & Tracer diffusion flux of component $i$ \\
\hline$D_{i}^{*}$ & Tracer diffusion coefficient of component $i$ & $\vec{v}_{\text {oxide /GAS }}$ & $\begin{array}{l}\text { Interface velocity between perovskite and } \\
\text { GAS phase }\end{array}$ \\
\hline
\end{tabular}

\section{Model descriptions}

\subsection{Thermodynamic model}

Two sets of thermodynamic descriptions for the La-Co-O system are available in the literature. One is from Yang et al. [23], while the other is from Zhang et al. included as part of Zhang's PhD thesis published online [22]. Both were developed using the CALPHAD methodology and used experimental data from the literature to optimize parameters for the Gibbs energy functions of different phases in La-Co-O. Also, the same model was used for the $\mathrm{LaCoO}_{3-\delta}$ perovskite phase. The difference lies in how the Gibbs energy function parameters were derived and how well the 
calculation fits with the experimental data. Yang's work provides a good agreement with experimentally measured oxygen non-stoichiometry data. However, the phase diagrams calculated using their database are in contradiction with experimental findings with regard to stability of the $\mathrm{LaCoO}_{3-\delta}$ perovskite phase. Zhang et al. adopted a different strategy in modeling the La-Co-O system, where different types of data were all taken into account. This gives a satisfactory reproduction of both oxygen non-stoichiometry and phase diagram data. In addition to La-Co-O, Zhang et al. have further extended the database to the entire La-Sr-Co-Fe-O system. Later Yang's colleague, Y. Zhong, co-authored a number of interesting papers [24-28] related to the thermodynamics of the La-Sr-Co-Fe-O system, in which all the thermodynamic calculations are based on the database developed by Zhang et al. [22]. For the problem at hand, where accurate description of the phase diagram of La-Co-O is important, the database developed by Zhang et al. is more appropriate and was thus adopted in the work.

$\mathrm{LaCoO}_{3-\delta}$ has an $\mathrm{ABO}_{3}$-type perovskite structure, with the A site occupied by La cations and vacancies, the $\mathrm{B}$ site containing $\mathrm{Co}$ cations and vacancies, and the third sublattice (O site) containing oxygen anions and vacancies. Both $\mathrm{Co}^{3+}, \mathrm{Co}^{2+}$ and $\mathrm{Co}^{4+}$ were introduced on the $\mathrm{B}$ site so that the model can describe charge disproportionation and oxygen non-stoichiometry variations [22]. Consequently, the perovskite $\mathrm{LaCoO}_{3-\delta}$ is modeled as $\left(\mathrm{La}^{3+}, \mathrm{Va}\right)_{1}\left(\mathrm{Co}^{2+}, \mathrm{Co}^{3+}, \mathrm{Co}^{4+}, \mathrm{Va}\right)_{1}\left(\mathrm{O}^{2-}, \mathrm{Va}\right)_{3}$, while the phases $\mathrm{CO}_{3} \mathrm{O}_{4}, \mathrm{La}_{2} \mathrm{O}_{3}$ and $\mathrm{CoO}$ are treated as stoichiometric compound.

The Gibbs energy function of the perovskite phase is given by the following expression:

$G_{m}^{\text {perovskite }}=\sum_{i} \sum_{j} \sum_{k} y_{i} y_{j} y_{k}{ }^{0} G_{i: j: k}^{\text {perovskite }}+R T\left(\sum_{i} y_{i} \ln y_{i}+\sum_{j} y_{j} \ln y_{j}+3 \sum_{k} y_{k} \ln y_{k}\right)+{ }^{E} G_{m}^{\text {perovskite }}$

where $i, j$, and $k$ represent the constituents in the first, second and third sublattice, respectively. $y_{i}$ denotes the site-fraction of $i .{ }^{o} G_{i: j: k}^{\text {perovskite }}$ is the Gibbs energy of the end-member component $(i)_{1}(j)_{1}(k)_{3}$. The second term is the configurational entropy, and ${ }^{E} G_{m}^{\text {perovskite }}$ is the excess Gibbs energy. The chemical potential of component $i$ can be calculated according to the following formula:

$\mu_{i}=G_{m}^{\gamma}+\sum_{j=2}^{n}\left(\delta_{i j}-x_{j}\right)\left(\frac{\partial G_{m}^{\gamma}}{\partial x_{j}}\right), \quad \delta_{i j}= \begin{cases}1 & i=j \\ 0 & i \neq j\end{cases}$

where $G_{m}^{\gamma}$ is the molar gibbs free energy of phase $\gamma, x_{j}$ represents the mole fraction of component $j$, $n$ is the total number of components in the $\gamma$ phase.

The relationship between the macroscopic mole fractions and the microscopic site fraction is given by the following equations, from which the atomistic features of the process are identified at the same time.

$x_{L a}=\frac{y_{L a^{3+}}^{1} \cdot 1}{\left(1-y_{V a}^{1}\right) \cdot 1+\left(1-y_{V a}^{2}\right) \cdot 1+\left(1-y_{V a}^{3}\right) \cdot 3}$

$x_{C o}=\frac{y_{\mathrm{Co}^{2+}}^{2} \cdot 1+y_{\mathrm{Co}^{3+}}^{2} \cdot 1+y_{\mathrm{Co}^{4+}}^{2} \cdot 1}{\left(1-y_{V a}^{1}\right) \cdot 1+\left(1-y_{V a}^{2}\right) \cdot 1+\left(1-y_{V a}^{3}\right) \cdot 3}$

$x_{O}=\frac{y_{O^{2-}}^{3} \cdot 3}{\left(1-y_{V a}^{1}\right) \cdot 1+\left(1-y_{V a}^{2}\right) \cdot 1+\left(1-y_{V a}^{3}\right) \cdot 3}$ 
where $y_{i}^{j}$ is the site fraction of $i$ in the $j_{t h}$ site $\left(j=1_{\text {st }}, 2_{\mathrm{nd}}, 3_{\mathrm{rd}}\right.$ sites; $i=\mathrm{La}^{3+}, \mathrm{Co}^{2+}, \mathrm{Co}^{3+}, \mathrm{Co}^{4+}, \mathrm{O}^{2-}$,

or Va). Meanwhile, $y_{\mathrm{La} 3+}, y_{\mathrm{Co} 2+}, y_{\mathrm{Co} 3+}, y_{\mathrm{CO} 4+}$, and $y_{\mathrm{O} 2-}$ implicitly inter-correlate with the electric neutrality condition and through the variation of the Gibbs free energy in the thermodynamic description:

$$
3 \cdot y_{\mathrm{O}^{2-}}^{3} \cdot 2=1 \cdot y_{\mathrm{La}^{3+}}^{1} \cdot 3+1 \cdot y_{\mathrm{Co}^{2+}}^{2} \cdot 2+\cdot 1 \cdot y_{\mathrm{Co}^{3+}}^{2} \cdot 3+1 \cdot y_{\mathrm{Co}^{4+}}^{2} \cdot 4
$$

Fig. 1(a) presents the site fraction of the Co cations, La cation and $\mathrm{O}$ anion as a function of temperature in air calculated with the thermodynamic parameters $\left({ }^{o} G_{i: j: k}^{\text {perovkite }},{ }^{E} G_{m}^{\text {perovskite }}\right)$ from Ref.[22]. $\mathrm{LaCoO}_{3-\delta}$ shows no charge disproportionation at low temperature, while $\mathrm{Co}^{2+}$ and $\mathrm{Co}^{4+}$ start forming at approximately $700 \mathrm{~K}$. Moreover, the site fraction of $\mathrm{Co}^{3+}$ decreases with temperature, while the site fractions of $\mathrm{Co}^{2+}$ and $\mathrm{Co}^{4+}$ increase with temperature. The site fraction of $\mathrm{O}^{2-}$ starts reducing at approximately $1350 \mathrm{~K}$. The calculated site fractions of the different ions as a function of oxygen partial pressure at $1073 \mathrm{~K}$ are shown in Fig. 1(b). At low oxygen partial pressure, the oxygen non-stoichiometry and charge disproportionation between different Co-valence states are obvious and interrelated with the defect reaction model. The electroneutrality is maintained implicitly. As the $\mathrm{PO}_{2}$ increases, the oxygen deficiency and charge disproportionation diminish gradually. As shown in Fig. 1, the site fraction of $\mathrm{La}^{3+}$ remains almost constant at different oxygen partial pressures and is very close to 1 . The site fraction of A-site vacancy is hence close to zero $\left(10^{-12}\right.$ as shown in Fig. 1b). $10^{-12}$ is the numerical limit set for site fractions in Thermo-Calc/DICTRA software, i.e. the real Va fraction given by the thermodynamic description is lower and most probably dependent on oxygen partial pressure and temperature. This numerical limit can be changed but this might lead to an unstable simulation or long computational times, which was hence avoided in our work. However, since La is much slower than Co, the chosen numerical limit should have no influence on the subsequent simulation.
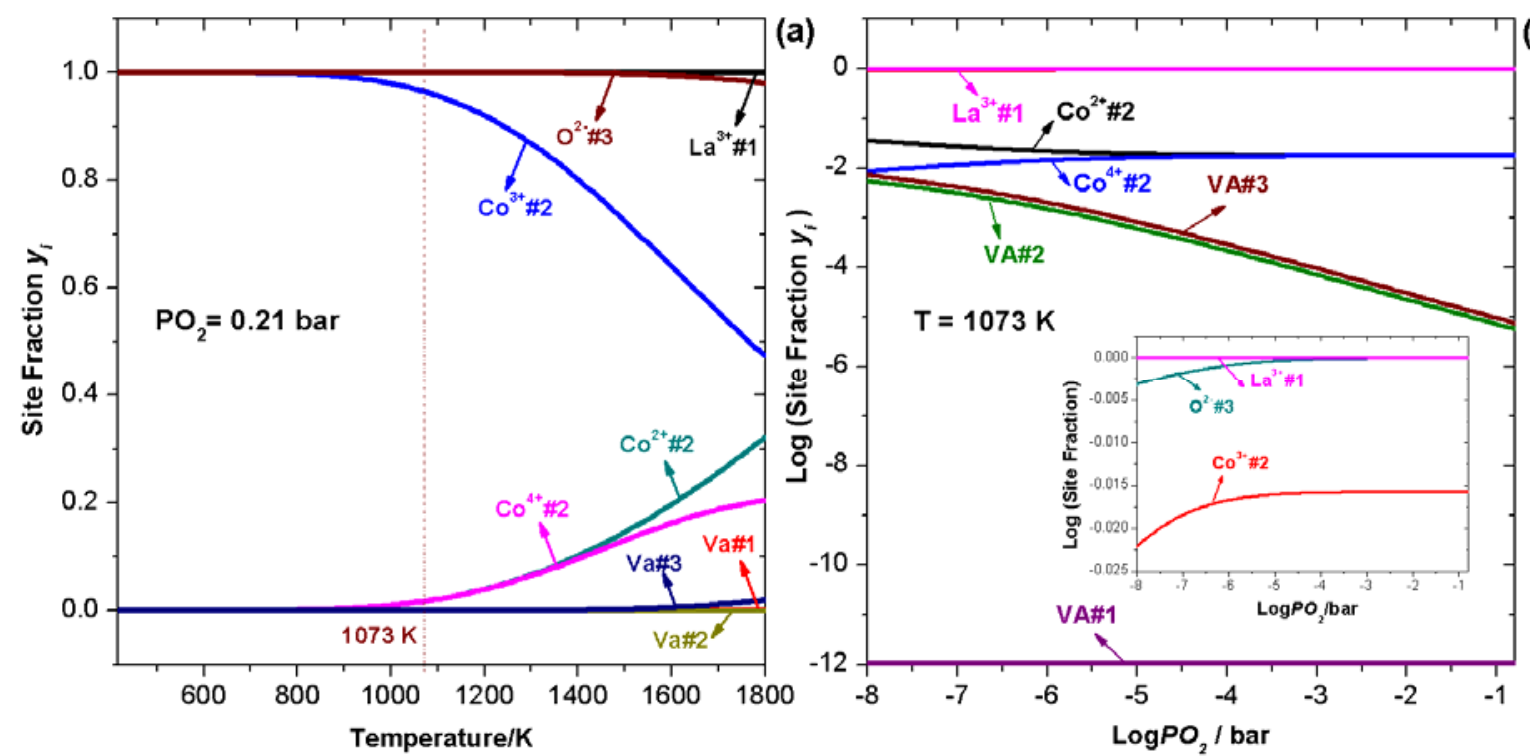

Fig. 1. Site fractions in $\mathrm{LaCoO}_{3-\delta}$ (a) in air as a function of temperature and (b) as a function of oxygen partial pressures at $1073 \mathrm{~K}$. Va\#1 means site fraction of vacancy in the first sublattice, $\mathrm{La}^{3+} \# 1$ means site fraction of $\mathrm{La}^{3+}$ in the first sublattice, and so on for the other symbols. 
The calculated $\mathrm{PO}_{2}$-composition phase diagram of the ternary La-Co-O system at $1073 \mathrm{~K}$ is shown in Fig. 2. In the present work, an oxygen partial pressure range from $10^{-4}$ bar to 1 bar is used to investigate the influence of an oxygen potential gradient on the demixing and decomposition process in $\mathrm{LaCoO}_{3-\delta}$. This is considered a relevant span for oxygen transferring membrane workings with air on feed side and a vacuum on the permeate side.

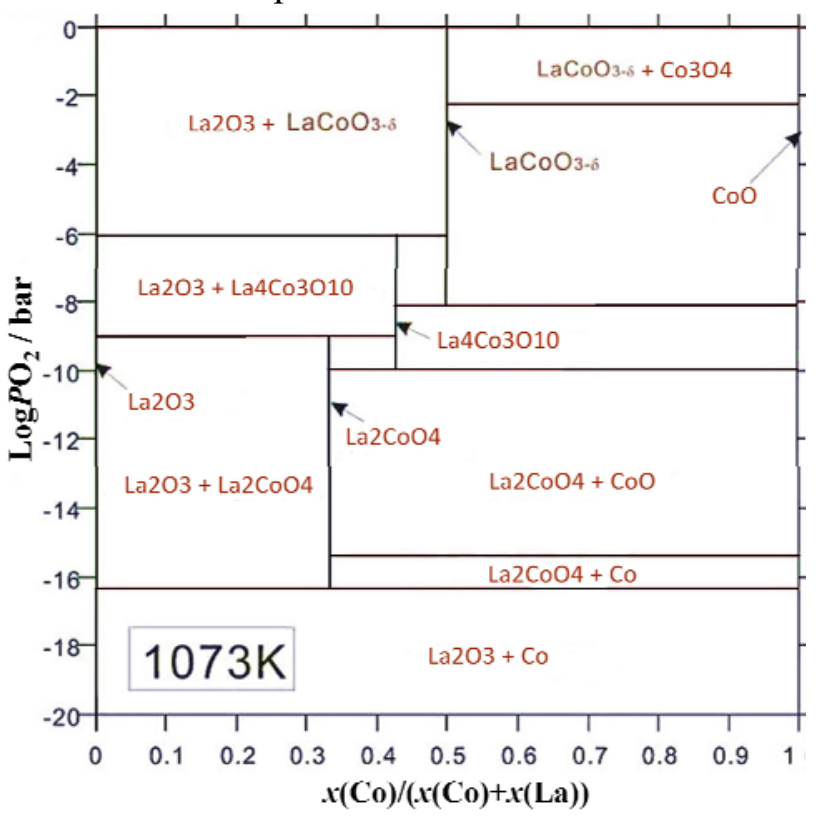

Fig. 2. Calculated isothermal $P_{2}$-composition phase diagram at $1073 \mathrm{~K} . x(\mathrm{Co})$ and $x(\mathrm{La})$ are mole fraction of Co and La respectively.

\subsection{Kinetic model}

The electrochemical potential of component $i$ is defined as $\eta_{i}=\mu_{i}+z_{i} F \varphi$, where $\mu$ is the chemical potential, $\varphi$ the electric potential, $z_{i}$ the charge of species $i$, and $F$ Faraday's constant. The flux of the ions based on Onsager's theory (neglecting cross-coefficients) in the lattice-fixed reference frame (The form of Fick's law depends on how one defines the position of a certain point, that is, the frame of reference. The number-fixed reference frame is to count the number of atoms on each side of the point of interest and to require that these numbers stay constant, while the lattice-fixed reference frame defines the position of a point relative to an inert marker in the system at the points of interest [29].) is as follows:

$$
\begin{aligned}
& \vec{J}_{i}=-L_{i i} \nabla \eta_{i}=-\frac{M_{i}^{*} x_{i}}{V_{m}}\left(\nabla \mu_{i}+z_{i} F \nabla \varphi\right) \\
& \left(i=L a^{3+}, \mathrm{Co}^{2+}, \mathrm{Co}^{3+}, \mathrm{Co}^{4+}, \mathrm{O}^{2-}\right)
\end{aligned}
$$

where $M_{i}^{*}$ is the diffusion mobility of the component $i$. After a series of reasonable assumptions for this material (most important ones being Eqs.(A.1-A.9), see further in Appendix A), Eq. (5) can be simplified to 
$\vec{J}_{i}=-\frac{M_{i}^{*} x_{i}}{V_{m}} \nabla \mu_{i}$

Therefore, we can consider the diffusion of $\mathrm{La}, \mathrm{Co}$ and $\mathrm{O}$ in the target system without considering their charge; i.e., the contribution of the electric potential gradient to the diffusion flux is neglected. In addition, $\mathrm{O}^{2-}$ diffuses much faster than the cations and a flux of $\mathrm{O}^{2-}$ through the oxide system prevails when an oxygen potential gradient is present. Since the electronic conduction in $\mathrm{LaCoO}_{3-\delta}$ is much faster than the oxygen ion conduction, different $\mathrm{O}^{2-}$ concentrations can be compensated fast by the redox reaction everywhere inside the oxide. It should be note that, in the CALPHAD modeling and DICTRA simulations, we do not model electrons and electron holes, even though we do consider charged species (cation and oxygen ion), and in the subsequent DICTRA simulation, the diffusion species are considered to be neutral.

\subsubsection{Diffusion in single phase $\mathrm{LaCoO}_{3-\delta}$}

The simulations were performed with the DICTRA software package, in which the multicomponent diffusion problems are treated by combining thermodynamic and kinetic databases. Thus, before the DICTRA simulation, a reliable set of diffusion mobilities in the $\mathrm{LaCoO}_{3-\delta}$ phase must first be established.

Considering the characteristics of the oxide crystal, the ions can diffuse only by virtue of their own thermal defects as migration carriers so that electroneutrality can be preserved; i.e., the diffusion flux of the ions is only related to their own potential gradients. Therefore, the lattice-fixed reference frame (atomistic scale) is chosen for the present case; the velocity of the lattice-fixed reference frame relative to the number-fixed reference frame is given by $\vec{v}=-V_{m} \sum_{i=1}^{n} \vec{J}_{i}$

The diffusion flux of $\mathrm{La}^{3+}$, Co ions and $\mathrm{O}^{2-}$ in the single phase can be expressed along the direction of $z$ in a lattice-fixed reference frame (see Appendix B) [17,18],

$$
\begin{aligned}
\vec{J}_{L a} & =-\left(x_{L a} y_{V a}^{1} M_{L a V a}^{1}\right) \frac{1}{V_{m}} \nabla \mu_{L a}=-\left(x_{L a} y_{V a}^{1} M_{L a V a}^{1}\right) \frac{1}{V_{m}}\left(\left(\frac{\partial \mu_{L a}}{\partial x_{L a}}-\frac{\partial \mu_{L a}}{\partial x_{O}}\right) \frac{\partial x_{L a}}{\partial z}+\left(\frac{\partial \mu_{L a}}{\partial x_{C o}}-\frac{\partial \mu_{L a}}{\partial x_{O}}\right) \frac{\partial x_{C o}}{\partial z}\right) \\
\vec{J}_{C o} & =-\left(x_{C o} y_{V a}^{2} M_{C o V a}^{2}\right) \frac{1}{V_{m}} \nabla \mu_{C o} \\
& =-\left(x_{C o} y_{V a}^{2} M_{C o V a}^{2}\right) \frac{1}{V_{m}}\left(\left(\frac{\partial \mu_{C o}}{\partial x_{L a}}-\frac{\partial \mu_{C o}}{\partial x_{O}}\right) \frac{\partial x_{L a}}{\partial z}+\left(\frac{\partial \mu_{C o}}{\partial x_{C o}}-\frac{\partial \mu_{C o}}{\partial x_{O}}\right) \frac{\partial x_{C o}}{\partial z}\right)
\end{aligned}
$$

$$
\vec{J}_{O}=-\left(x_{O} y_{V a}^{3} M_{\text {OVa }}^{3}\right) \frac{1}{V_{m}} \nabla \mu_{O}=-\left(x_{O} y_{V a}^{3} M_{O V a}^{3}\right) \frac{1}{V_{m}}\left(\left(\frac{\partial \mu_{O}}{\partial x_{L a}}-\frac{\partial \mu_{O}}{\partial x_{O}}\right) \frac{\partial x_{L a}}{\partial z}+\left(\frac{\partial \mu_{O}}{\partial x_{C o}}-\frac{\partial \mu_{O}}{\partial x_{O}}\right) \frac{\partial x_{C o}}{\partial z}\right)
$$

Here $y_{V a}^{j}$ is the fraction of vacant lattice sites on the sublattice $j$ and the mobility $M_{i}^{j}$ is here defined as: $M_{i}^{j}=y_{V a} M_{i V a}^{j}$, which in general depends on composition, temperature, and pressure.

The kinetic parameter $M_{i V a}^{j}$ has the common format:

$$
M_{i V a}^{j}=M_{i V a}^{j 0} \exp (-Q / R T)
$$


When considering diffusion, we shall neglect the difference between Co-ions and thus can simply assume

$$
M_{\mathrm{Co}^{2+} \mathrm{Va}}^{2}=M_{\mathrm{Co}^{3+} \mathrm{Va}}^{2}=M_{\mathrm{Co}^{4+} \mathrm{Va}}^{2}=M_{\mathrm{CoVa}}^{2}
$$

It should be noted that, the diffusion coefficient usually depends on the oxidation state of Co, which influences the size of the ion or more accurately the electronic density distribution around it. It is also well established in the literature that the diffusion coefficient of $\mathrm{B}$ ions in $\mathrm{ABO}_{3}$ depends strongly on the concentration of A-site vacancies. Due to lack of any data, we make the above simplified assumptions.

Then, we have six chemical diffusivities in total as

$\mathrm{D}_{L a L a}=-\left(x_{L a} y_{V a}^{1} M_{L a V a}^{1}\right)\left(\frac{\partial \mu_{L a}}{\partial x_{L a}}-\frac{\partial \mu_{L a}}{\partial x_{O}}\right)$

$\mathrm{D}_{\text {LaCo }}=-\left(x_{L a} y_{V a}^{1} M_{L a V a}^{1}\right)\left(\frac{\partial \mu_{L a}}{\partial x_{C o}}-\frac{\partial \mu_{L a}}{\partial x_{O}}\right)$

$\mathrm{D}_{\mathrm{OLa}}=-\left(x_{O} y_{V a}^{3} M_{O V a}^{3}\right)\left(\frac{\partial \mu_{O}}{\partial x_{L a}}-\frac{\partial \mu_{O}}{\partial x_{O}}\right)$

$\mathrm{D}_{\mathrm{OCo}}=-\left(x_{O} y_{V a}^{3} M_{O V a}^{3}\right)\left(\frac{\partial \mu_{O}}{\partial x_{C o}}-\frac{\partial \mu_{O}}{\partial x_{O}}\right)$

Eqs. (12-14) are the theoretical formula for the development of the mobility database based on the experimental data later on.

According to the above equations, the group of diffusion-governed equations based on Fick' $\mathrm{s}$ $2^{\text {nd }}$ law expressed in the lattice-fixed reference frame are as follows,

$$
\left\{\begin{array}{l}
\frac{\partial C_{L a}}{\partial t}=-\frac{\partial \vec{J}_{L a}}{\partial z}=\frac{\partial}{\partial z}\left(D_{L a L a} \frac{\partial C_{L a}}{\partial z}\right)+\frac{\partial}{\partial z}\left(D_{L a C o} \frac{\partial C_{C o}}{\partial z}\right) \\
\frac{\partial C_{C o}}{\partial t}=-\frac{\partial \vec{J}_{C o}}{\partial z}=\frac{\partial}{\partial z}\left(D_{C o L a} \frac{\partial C_{L a}}{\partial z}\right)+\frac{\partial}{\partial z}\left(D_{C o C o} \frac{\partial C_{C o}}{\partial z}\right) \\
\frac{\partial C_{O}}{\partial t}=-\frac{\partial \vec{J}_{O}}{\partial z}=\frac{\partial}{\partial z}\left(D_{O L a} \frac{\partial C_{L a}}{\partial z}\right)+\frac{\partial}{\partial z}\left(D_{O C o} \frac{\partial C_{C o}}{\partial z}\right)
\end{array}\right.
$$

Based on the above Eqs. (5-15), diffusion in the $\mathrm{LaCoO}_{3-\delta}$ single phase can be treated. By setting an oxygen potential gradient in the oxide as dictated by the boundary conditions, the potential gradients of La and Co can form, which provide driving force for cation diffusion that may result in demixing and even decomposition.

\subsubsection{Diffusion in multiphase mixtures}

Considering that second phases may form during kinetic decomposition, the diffusion model in multiphase mixtures needs to take into account changes in transport properties on decomposition. Here, a homogenization approach [31] is used to treat the diffusion in multiphase mixtures in a 1-D geometry. Different oxygen activity boundary conditions are set on the two sides of the membrane to reproduce the experimental oxygen potential gradient. In order to apply the homogenization approach [31] in the present case, the following hypotheses are made, (1) the treatment is limited to 1-D, and the phase molar volume $V_{m}$ is assumed to be constant; (2) the diffusion is solved in the lattice-fixed frame of reference and it is assumed that the local fraction of vacancies always 
corresponds to equilibrium; (3) only bulk diffusion is considered (i.e., no significant contribution from grain boundaries); (4) local thermodynamic equilibrium conditions are assumed; (5) All other phases but $\mathrm{LaCoO}_{3-\delta}$ are assumed not to allow any diffusion; (6) the phases have average kinetic properties and chemical potentials corresponding, locally, to equilibrium. The same numerical procedure is applied across the entire region without considering interfaces.

Based on absolute reaction rate theory arguments [32] in the lattice-fixed reference frame, the following flux expression was used to describe the diffusion phenomenon in a multiphase sample,

$$
J_{k}=-\frac{M_{k}^{\text {eff }} R T}{V_{m} \Delta \widetilde{z}} \sqrt{x_{k}^{1} x_{k}^{2}} 2 \sinh \left(\frac{\Delta \mu_{k}^{\text {l.eq. }}}{2 R T}\right)
$$

where $\mu_{k}^{\text {l.eq. }}$ signifies the local chemical potential corresponding to the local equilibrium in Gibbs energy. $M_{k}^{\text {eff }}$ is the local effective mobility. $x_{k}^{1}$ and $x_{k}^{2}$ denote the local overall mole fractions of species $k$ on plane/source 1 and 2, regardless of the number of phases present locally, $\Delta \widetilde{z}$ is the grid spacing.

For most phases in the La-Co-O system, the volume fractions of new phases during the kinetic decomposition process are so small that no continuous network of particles can form throughout the oxide. Thus, the Wiener upper bounds model [33,34], derived on the basis of the fractions of various phases, are used in the present work, and are defined from the assumption of uniform force, i.e., the uniform chemical potential gradients,

$M_{k}^{e f f}=\sum_{\alpha=1}^{n} f^{\alpha} M_{k}^{\alpha}$.

where $f^{\alpha}$ is the volume fraction of phase $\alpha$, and $M_{k}^{\alpha}$ is the mobility of species $k$ in phase $\alpha$, which

has been defined in the previous Section 2.2.1. The homogenization approach relies on the use of chemical potential gradients instead of concentration gradients. When setting different oxygen activity boundary conditions on both sides of the $\mathrm{LaCoO}_{3-\delta}$ oxide, a local chemical potential gradient is developed across the entire region gradually, accompanied by kinetic demixing of $\mathrm{La}$ and Co due to the difference in the diffusion mobility of cations.

For the present case, there are initially two phase boundaries (Low $\mathrm{PO}_{2} \mathrm{GAS}-\mathrm{I} / \mathrm{LaCoO}_{3}-\delta$ and $\mathrm{LaCoO}_{3-\delta} / \mathrm{High} \mathrm{PO}_{2}$ GAS-II). The phase transformation is treated as a moving phase boundary problem [32]. Both of the diffusion flux at the two interfaces adjacent to GAS-I and GAS-II can be written as,

$$
\begin{aligned}
& \vec{v}_{\text {oxide/GAS }} \frac{x_{O}^{\text {oxide }}}{V_{m}^{\text {oxide }}}-\vec{v}_{G A S / \text { oxide }} \frac{1}{V_{m}^{G A S}}=\vec{J}_{O}^{\text {oxide }}-\vec{J}_{O}^{G A S} \\
& \vec{v}_{\text {oxide/GAS }}\left(\frac{x_{L a}^{\text {oxide }}}{V_{m}^{\text {oxide }}}+\frac{x_{C o}^{\text {oxide }}}{V_{m}^{\text {oxide }}}\right)-\vec{v}_{G A S / \text { oxide }}\left(\frac{x_{L a}^{G A S}}{V_{m}^{G A S}}+\frac{x_{C o}^{G A S}}{V_{m}^{G A S}}\right)=\vec{J}_{L a}^{\text {oxide }}+\vec{J}_{C o}^{\text {oxide }}-\left(\vec{J}_{L a}^{G A S}+\vec{J}_{C o}^{G A S}\right)
\end{aligned}
$$

$\vec{J}_{L a}^{G A S}=\vec{J}_{C o}^{G A S}=0$

$x_{L a}^{G A S}=x_{C o}^{G A S}=0$

$\vec{v}_{\text {oxide } / G A S}\left(\frac{x_{C o}^{\text {oxide }}}{V_{m}^{\text {oxide }}}+\frac{x_{L a}^{\text {oxide }}}{V_{m}^{\text {oxide }}}\right)=\vec{J}_{L a}^{\text {oxide }}+\vec{J}_{C o}^{\text {oxide }}$ 
, and can be solved for each phase. The velocity is here considered positive in the direction towards the high $\mathrm{PO}_{2}$ side. Eq. (18) indicates a positive cation diffusion flux, suggesting the motion of the oxide surfaces to the side of high $\mathrm{PO}_{2}$ with the velocity towards a common direction. The interfacial velocity can be expressed as Eq. (19),

$$
\vec{v}_{\text {oxide } / G A S}=V_{m}^{\text {oxide }}\left(\vec{J}_{\text {La }}^{\text {oxide }}+\vec{J}_{\text {Co }}^{\text {oxide }}\right) /\left(x_{C o}^{\text {oxide }}+x_{L a}^{\text {oxide }}\right)
$$

\section{Initial settings and input parameters for DICTRA simulation}

To predict the kinetic demixing phenomena accurately, simulation conditions were chosen to be consistent with real service conditions, including the geometry and oxygen potential gradient. The simulation was performed in a one-dimensional (1-D) tubular domain with 150 linear grid-lines. The thickness of the $\mathrm{LaCoO}_{3-\delta}$ oxygen membrane is set to $1 \mathrm{~mm}$ (i.e., $1 \times 10^{-3} \mathrm{~m}$ ) in accordance with typical experimental conditions. The flux of cation components is set to zero and the activity of oxygen is set to two different prescribed values at both the left and right boundaries of the $\mathrm{LaCoO}_{3-\delta}$ oxide region, which is called the gas boundary condition in DICTRA software. It should be noted that the gas phase is included in DICTRA in a particular way, it is included only in the thermodynamic calculation (the boundary conditions establishes the driving force) but it is not included in the kinetic calculations.

Fig. 3 shows a schematic diagram of $\mathrm{LaCoO}_{3-\delta}$ oxide exposed to an oxygen potential gradient i.e., established by different gas mixtures on the two sides. Fig 3(a) depicts the chemical potential gradients of the chemical components $\mathrm{La}, \mathrm{Co}$, and $\mathrm{O}$, and Fig. 3(b) the fluxes of the cations, $\mathrm{La}^{3+}$ and $\mathrm{Co}^{3+}$ and oxygen anion $\mathrm{O}^{2-}$. Oxygen ions diffuse from the high $\mathrm{PO}_{2}$ side to the low $\mathrm{PO}_{2}$ side; then, the contrary chemical potential gradients of the La and Co components are induced as a consequence of the Gibbs-Duhem relationship at constant temperature and pressure: $x_{L a} \nabla \mu_{L a}+x_{C o} \nabla \mu_{C o}+x_{O} \nabla \mu_{O}=0$, which leads to the diffusion flux of $\mathrm{La}^{3+}$ and Co cations in the opposite direction. With the movement of the cations from the low $\mathrm{PO}_{2}$ side to the high $\mathrm{PO}_{2}$ side, both of the oxide surfaces shift to the side of high oxygen potential. Fig 3(c) shows a schematic diagram of the oxygen membrane with tubular geometry simulated in the present work. DICTRA can adopt also other types of geometries, such as linear or spherical. Tubular and linear are both relevant to the present study. The influence of these two different geometries on the simulation results and on the simulation speed was hence investigated first. No noticeable difference was found. As the tubular geometry is closer to the practical application of oxygen membrane, this was adopted for all the simulations presented. 


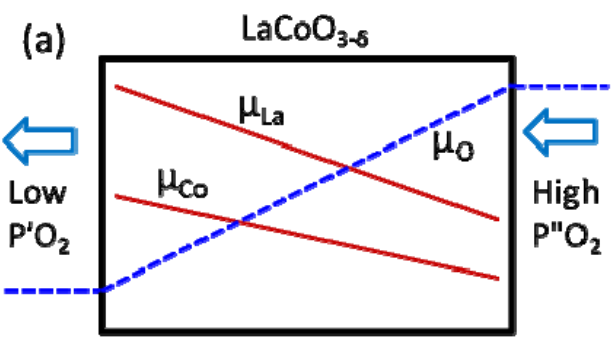

(b)

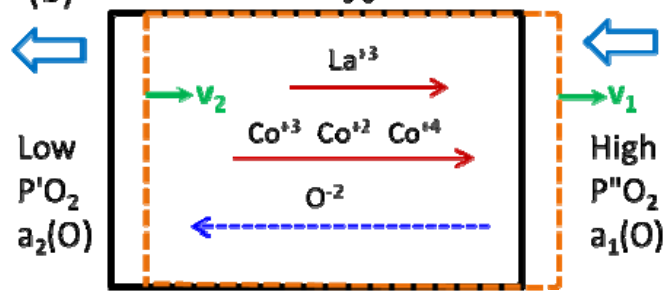

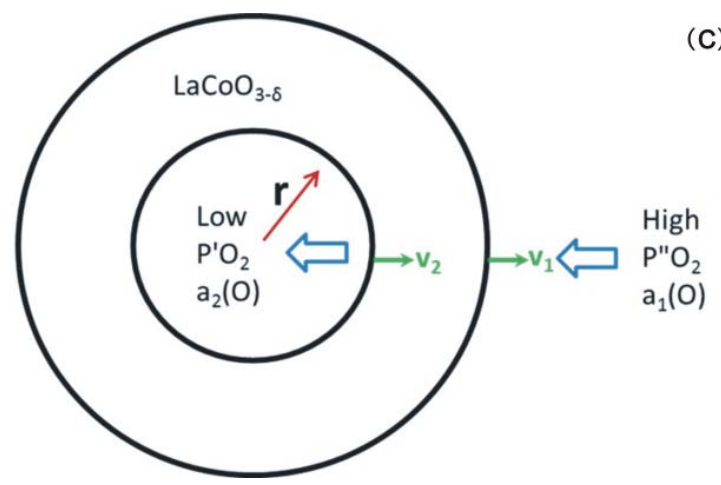

(C)

Fig. 3. Schematic diagram of $\mathrm{LaCoO}_{3-\delta}$ oxide under an oxygen potential gradient. (a) Chemical potential gradients of the chemical components $\mathrm{La}, \mathrm{Co}$, and $\mathrm{O}$. (b) Fluxes of the cations, $\mathrm{La}^{3+}$ and $\mathrm{Co}^{3+}$, and the oxygen anion $\mathrm{O}^{2-}$. (c) The simulated schematic diagram of oxygen membrane with tubular geometry.

The initial constituents, phases, temperature and oxygen activity boundary conditions in the present simulations are listed in Table 2. Due to the fact that the $\mathrm{LaCoO}_{3-\delta}$ perovskite phase has very limited composition range, i.e. the La/Co ratio is very close to 1 , we need to explicitly specify enough digits ( 7 decimals in this case) for the composition in order to simulate cation and oxygen ion diffusion.

\section{Table 2}

List of constituents, phases, temperature and oxygen activity boundary conditions in the present simulations

\begin{tabular}{ccccccc}
\hline $\begin{array}{c}\text { Initial } \\
\text { phases }\end{array}$ & Composition (at.\%) & $P\left(\mathrm{O}_{2}\right)_{\mathrm{L}}$ & $P\left(\mathrm{O}_{2}\right)_{\mathrm{R}}$ & $T(\mathrm{~K})$ & Geometry & $\begin{array}{c}\text { Included } \\
\text { phases }\end{array}$ \\
\hline Perovskite & $\mathrm{La}_{0.5000188-\mathrm{Co}_{0.4999812-} \mathrm{O}_{3-\delta}}$ & $1 \times 10^{-4}$ bar & $0.21 \mathrm{bar}$ & 1073 & Tubular & $\begin{array}{c}\mathrm{La}_{2} \mathrm{O}_{3} \\
\mathrm{Co}_{3} \mathrm{O}_{4}\end{array} \quad \mathrm{CoO}$ \\
\hline
\end{tabular}

\section{Results and discussion}

\subsection{Diffusion mobilities for cations and oxygen ions}

The atomic mobility database of the perovskite phase in the La-Co-O system was developed and optimized based on the experimental data from [35-41] to provide reliable kinetic parameters for the present work. The tracer diffusion flux expression based on [21] in the lattice-fixed frame of reference is given by Eq. (20), 


$$
\begin{aligned}
\vec{J}_{L a^{*}} & =-\left(y_{L a^{*}}^{1} y_{V a}^{1} M_{L a V a}^{1}\right) \frac{1}{V_{m}} \nabla \mu_{L a}=-\left(y_{L a}^{1} y_{V a}^{1} M_{L a^{3+V a}}^{1}\right) \frac{1}{x_{L a}} R T \frac{\partial C_{L a^{*}}}{\partial z} \\
\vec{J}_{C o^{*}} & =-\left(y_{C o^{*}}^{2} y_{V a}^{2} M_{C o V a}^{2}\right) \frac{1}{V_{m}} \nabla \mu_{C o} \\
& =-\frac{1}{3}\left(y_{C 0^{2+}}^{2} y_{V a}^{2} M_{C 0^{2+V a}}^{2}+y_{C 0^{3+}}^{2} y_{V a}^{2} M_{C 0^{3+V a}}^{2}+y_{C 0^{4+}}^{2} y_{V a}^{2} M_{C 0^{4+V a}}^{2}\right) \frac{1}{x_{C o}} R T \frac{\partial C_{C 0^{*}}}{\partial z} \\
\vec{J}_{O^{*}} & =-\left(y_{O^{*}}^{3} y_{V a}^{3} M_{O V a}^{3}\right) \frac{1}{V_{m}} \nabla \mu_{O}=-\left(y_{O}^{3} y_{V a}^{3} M_{O^{2} V a}^{3}\right) \frac{1}{x_{O}} R T \frac{\partial C_{O^{*}}}{\partial z}
\end{aligned}
$$

Then, the tracer diffusion coefficients are,

$$
D_{L a}^{*}=\left(y_{L a}^{1} y_{V a}^{1} M_{L a^{3+V a}}^{1}\right) \frac{1}{x_{L a}} R T
$$

$D_{C o}^{*}=-\frac{1}{3}\left(y_{\mathrm{Co}^{2+}}^{2} y_{\mathrm{Va}}^{2} M_{\mathrm{Co}^{2+} \mathrm{Va}}^{2}+y_{\mathrm{Co}^{3+}}^{2} y_{V a}^{2} M_{\mathrm{Co}^{3+} \mathrm{Va}}^{2}+y_{\mathrm{Co}^{4+}}^{2} y_{V a}^{2} M_{\mathrm{Co}^{4+} \mathrm{Va}}^{2}\right) \frac{1}{x_{\mathrm{Co}}} R T$

$D_{O}^{*}=\left(y_{O}^{3} y_{V a}^{3} M_{O^{2}-V a}^{3}\right) \frac{1}{x_{O}} R T$

According to Eq. (21), the diffusion behavior strongly depends on the sublattice occupancy, which can also explain the much slower tracer diffusivity of La due to its low site fraction of vacancy, as shown in Fig. 1. As long as we know the tracer diffusivity, it is very easy to obtain the chemical diffusivity by equivalent substitution according to Eqs.(12-14) and Eq.(21). The mobilities in Eq. (21) were adjusted to the available experimental data from Refs. [35-41] by means of a non-linear, least-squares optimization. The resulting expressions of the mobilities are,

$$
\begin{aligned}
& M_{\mathrm{La}^{3+} V a}^{1}=3.5210 \times 10^{4} \exp (-322058.4 / R T) \quad \mathrm{m}^{2} / \mathrm{s} \\
& M_{C o^{2+} V a}^{2}=M_{C^{3+} V a}^{2}=M_{C 0^{4+} V a}^{2}=2.9303 \times 10^{-4} \exp (-193903.2 / R T) \quad \mathrm{m}^{2} / \mathrm{s} \\
& M_{O^{2} V a}^{3}=1.8620 \times 10^{-3} \exp (-150230.4 / R T) \quad \mathrm{m}^{2} / \mathrm{s}
\end{aligned}
$$

The calculated tracer diffusion coefficients (denoted by the symbol of DT in the figure) of La, $\mathrm{Co}$ and $\mathrm{O}$ as a function of temperature and oxygen partial pressure are shown in Fig. 4, in which they show good agreement with the experimental data. Therefore, the obtained mobility data for La, $\mathrm{Co}$ and $\mathrm{O}$ seem to represent well the kinetic properties in the $\mathrm{LaCoO}_{3-\delta}$ oxide at different temperatures and oxygen partial pressures. 

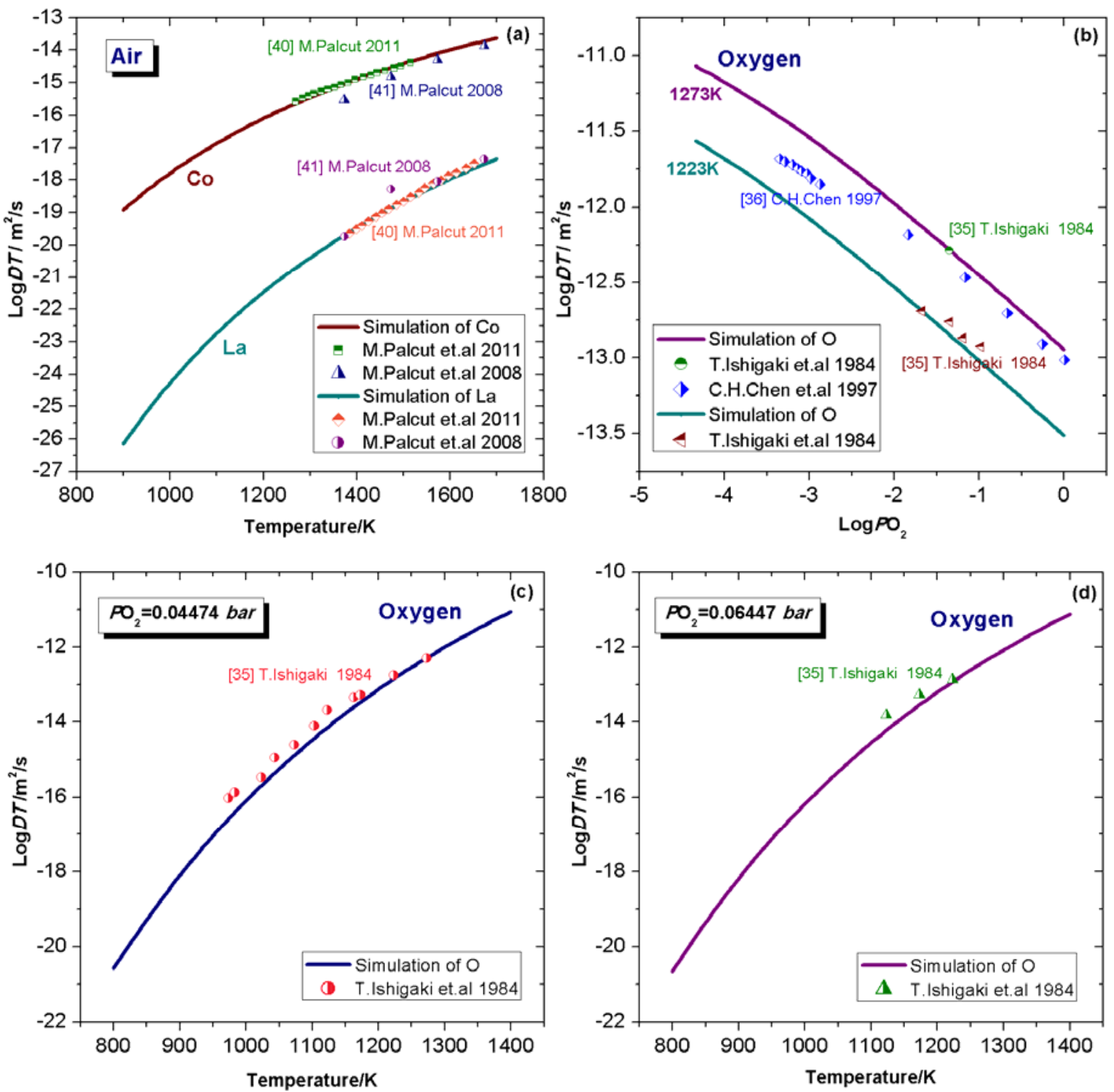

352

353

354

355

356

357

358

359

360

361

362

363

364

365

Fig. 4. Calculated (a) tracer diffusion coefficients of $\mathrm{La}$ and $\mathrm{Co}$ as a function of temperature, (b) tracer diffusion coefficients of $\mathrm{O}$ as a function of oxygen partial pressure, (c) as a function of temperature at $P \mathrm{O}_{2}=0.04474$ bar, and (d) at $\mathrm{PO}_{2}=0.06447$ bar, compared with the experimental data [35-41].

\subsection{Demixing concentration profiles}

The mole fractions of $\mathrm{La}$, Co and $\mathrm{O}$ satisfy the following mass conservation relationship, which explains the variation of the concentration profiles at $\mathrm{t}=86400 \mathrm{~s}$ (1 day) in the subsequent Fig. 5 .

$x_{L a}=x_{L a, p r v} \cdot f($ perovskite $)+x_{L a, L a O_{3}} \cdot f\left(\mathrm{La}_{2} \mathrm{O}_{3}\right)$

$x_{\mathrm{Co}}=x_{\mathrm{Co}, \mathrm{prv}} \cdot f($ perovskite $)+x_{\mathrm{Co}^{\mathrm{CO}} \mathrm{O}_{4}} \cdot f\left(\mathrm{Co}_{3} \mathrm{O}_{4}\right)+x_{\mathrm{Co}, \mathrm{CoO}} \cdot f(\mathrm{CoO})$

$x_{O}=x_{O, p r v} \cdot f($ perovskite $)+x_{O, G a s} \cdot f($ Gas $)+x_{\mathrm{O}_{\text {Co }} \mathrm{O}_{4}} \cdot f\left(\mathrm{Co}_{3} \mathrm{O}_{4}\right)+x_{\mathrm{OLa}_{2} \mathrm{O}_{3}} \cdot f\left(\mathrm{La}_{2} \mathrm{O}_{3}\right)+x_{\mathrm{O}, \mathrm{CoO}} \cdot f(\mathrm{CoO})$

The demixing concentration profiles from $\mathrm{t}=0 \mathrm{~s}$ to $\mathrm{t}=31000000 \mathrm{~s}$ (i.e., 1 year) in the $\mathrm{LaCoO}_{3-\delta}$ oxide are shown in Figs. 5 and 6 . It should be noted that the $x$-axis in all the figures starts from $z=0.01 \mathrm{~m}$ because the simulation was performed in a 1-D tubular domain with the inner radius of the tubular membrane being $0.01 \mathrm{~m}$ and the membrane thickness set to $1 \mathrm{~mm}\left(1 \times 10^{-3} \mathrm{~m}\right)$, as shown in Fig. 3 (c).The scale of y-axis is very small due to the limited non-stoichiometric range of the 
perovskite phase. The concentration gradients of La and Co are opposite to that of oxygen. The first stage, from $\mathrm{t}=0 \mathrm{~h}$ to $\mathrm{t}=24 \mathrm{~h}$ in Fig. 5, represents the development of the concentration gradients across the membrane due to the fast diffusion of oxygen. The second stage, from $\mathrm{t}=667 \mathrm{~h}$ to $\mathrm{t}=$ $8611 \mathrm{~h}$ in Fig. 6, is mainly influenced by the kinetic decomposition process. The ratio of $x(\mathrm{La})$ to $x(\mathrm{Co})$ in Figs. 5(d) and 6(d) confirms the enrichment of the faster Co cations at the higher $\mathrm{PO}_{2}$ side of the membrane, accompanied by the precipitation of Co-rich phases (Fig. 8a). The La/Co molar ratio continuously decreases over time at the high $\mathrm{PO}_{2}$ side, whereas it remains almost constant in the largest part of the membrane. The precipitation of Co-rich phases $\left(\mathrm{Co}_{3} \mathrm{O}_{4}\right.$ and $\left.\mathrm{CoO}\right)$ at the high $\mathrm{PO}_{2}$ side leaves behind a La-rich region (Fig. 5d) which leads to the formation of $\mathrm{La}_{2} \mathrm{O}_{3}$ (Fig. 8b). The mole fraction of $\mathrm{O}$ increases at the high $\mathrm{PO}_{2}$ side to values above the stoichiometric one, which is due to the fact that the $\mathrm{O}$ mole fraction is calculated based on all the $\mathrm{O}$-containing phases in the membrane (and similarly for all other elements), which in the case of $\mathrm{O}$ includes also the Gas phase $\mathrm{O}$ released upon decomposition of the perovskite phase. Table 3 presents the local phase composition at $z=0.010987 \mathrm{~m}$ near the high $\mathrm{PO}_{2}$ side at $\mathrm{t}=86400 \mathrm{~s}$, which clearly confirms the above phenomenon.

Table 3

Local phase composition at $z=0.010987 \mathrm{~m}$ near the high $P \mathrm{O}_{2}$ side at $\mathrm{t}=86400 \mathrm{~s}$

\begin{tabular}{ccccc}
\hline Phases & $x(\mathrm{O})($ at.\%) & $x(\mathrm{Co})($ at.\%) & $x(\mathrm{La})($ at.\%) & Phase fraction \\
\hline Perovskite & 0.60001 & 0.19999 & 0.20000 & 0.99958 \\
$\mathrm{Co}_{3} \mathrm{O}_{4}$ & 0.57143 & 0.42857 & -- & 0.00022 \\
Gas & 1.00000 & -- & -- & 0.00020 \\
Total composition & 0.60008 & 0.20000 & 0.19992 & -- \\
\hline
\end{tabular}

At $\mathrm{t}=31000000$ s (i.e., 1 year), the mole fraction of Co reaches 0.20900 at the high $\mathrm{PO}_{2}$ side. Accordingly, the mole fraction of $\mathrm{O}$ decreases to 0.59860 due to the formation of $\mathrm{Co}_{3} \mathrm{O}_{4}$ yielding an overall lower $\mathrm{O} /$ cation ratio, and the ratio $\mathrm{La} / \mathrm{Co}$ of 0.92378 deviates from the initial concentration ratio of 1.00007 . The enlarged region near $z=0.011 \mathrm{~m}$ is somewhat noisy, which is due to numerical fluctuations. In order to obtain a long-term (1year) simulation result within a reasonable time frame, the automatic transformation time step is adopted which results in a larger time step and faster simulation but at the cost of lower accuracy. As the general variation tendency of the profile conforms to the shorter period more accurate analysis, it is concluded that the larger time step does not affect the reliability of the overall results. 

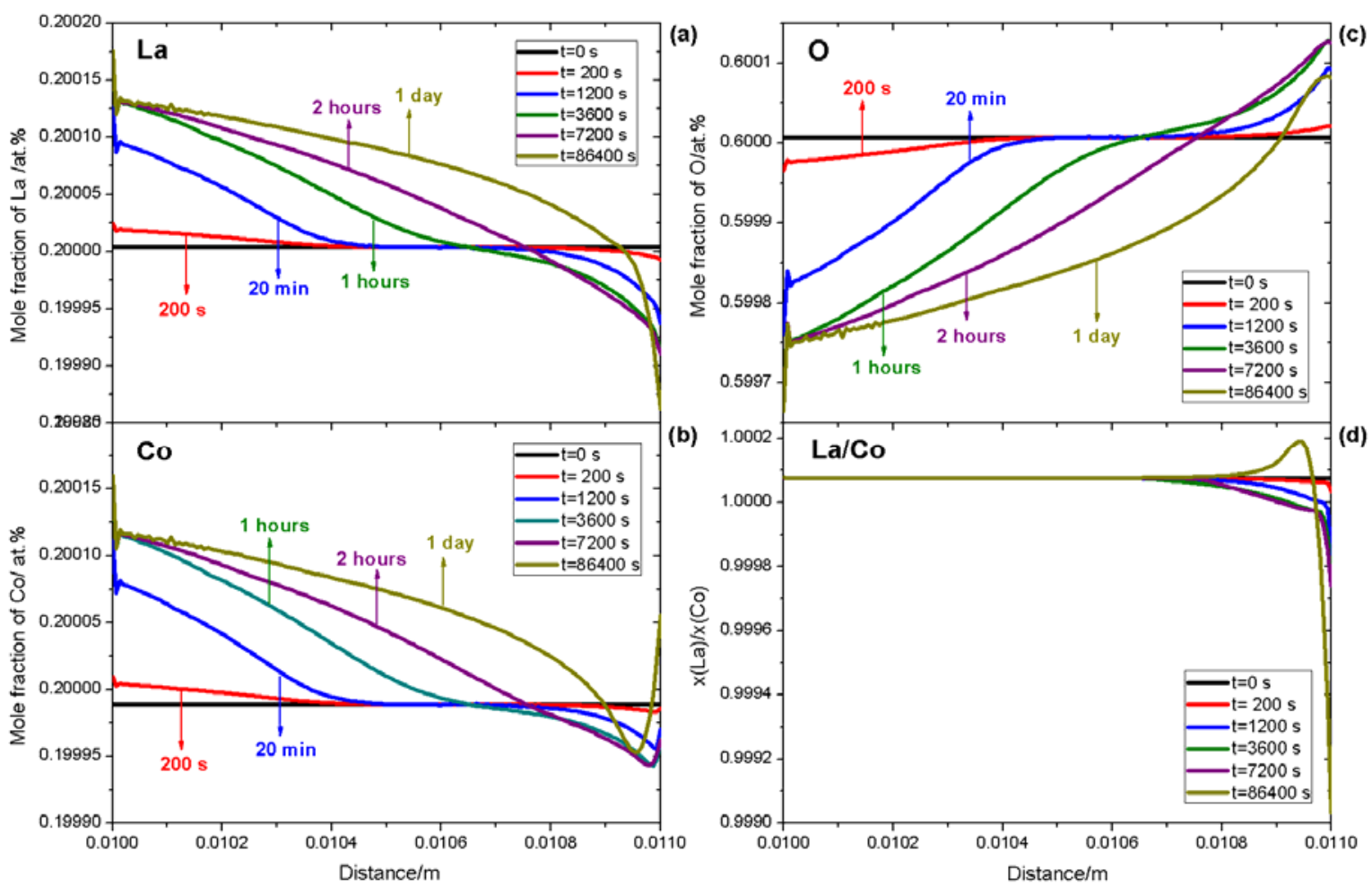

Fig. 5. Model-predicted demixing concentration profiles across the membrane at $1073 \mathrm{~K}$ from $\mathrm{t}=0 \mathrm{~h}$ to $\mathrm{t}=24 \mathrm{~h}$ :

(a) mole fraction of $\mathrm{La}$, (b) mole fraction of $\mathrm{Co}$, (c) mole fraction of $\mathrm{O}$, and (d) ratio of $x(\mathrm{La})$ to $x(\mathrm{Co})$.
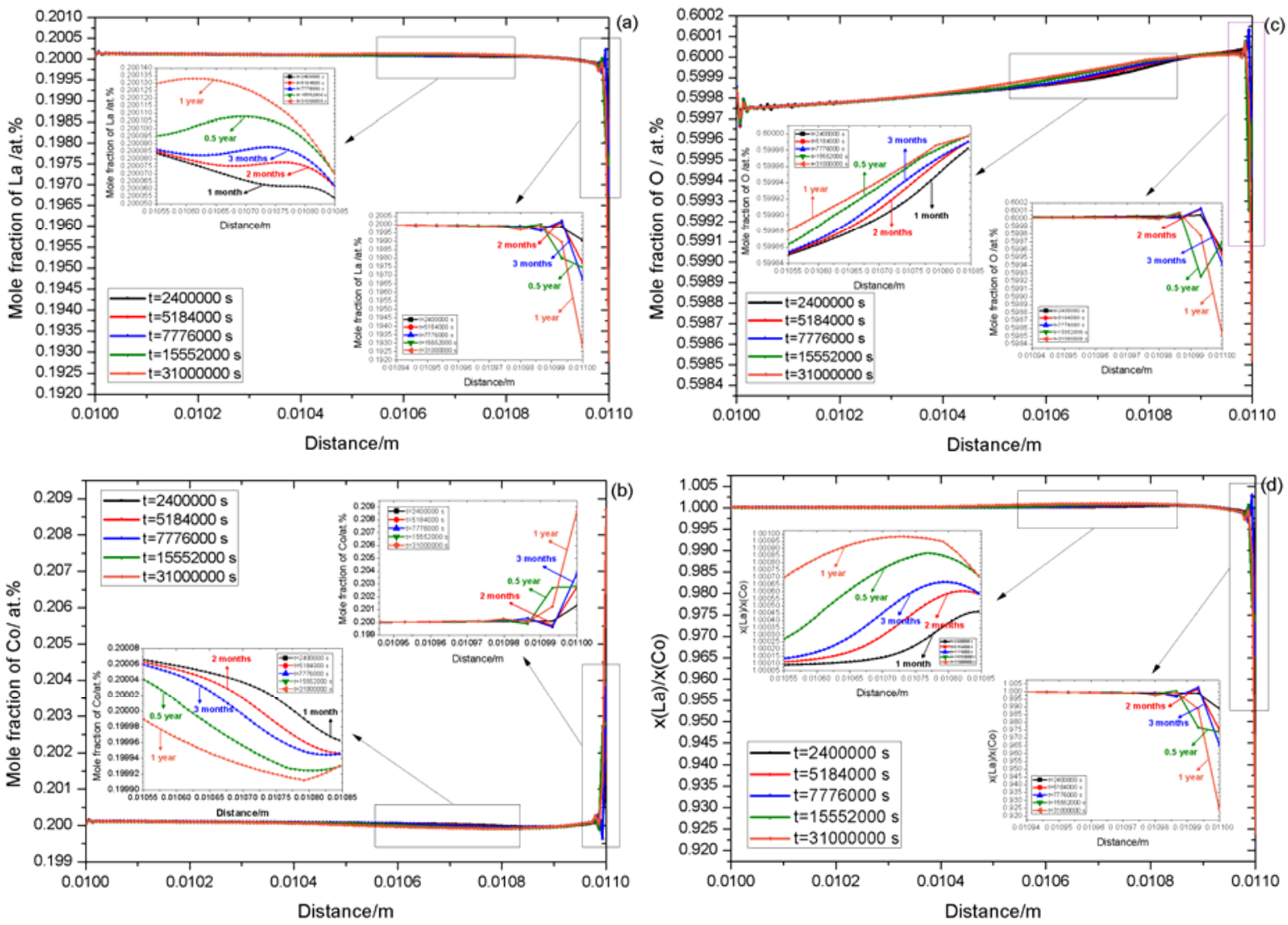

Fig. 6. Model-predicted concentration profiles across the membrane at $1073 \mathrm{~K}$ from $\mathrm{t}=667 \mathrm{~h}$ to $\mathrm{t}=8611 \mathrm{~h}$ : (a) mole fraction of $\mathrm{La}$, (b) mole fraction of $\mathrm{Co}$, (c) mole fraction of $\mathrm{O}$, and (d) ratio of $x(\mathrm{La})$ to $x(\mathrm{Co})$. 
The detailed diffusion behavior of different cations is further analyzed according to the site fraction profiles across the membrane at $1073 \mathrm{~K}$ from $\mathrm{t}=200 \mathrm{~s}$ to $\mathrm{t}=31000000 \mathrm{~s}$ in Fig. 7. From $\mathrm{t}=$ $200 \mathrm{~s}$ to $\mathrm{t}=86400 \mathrm{~s}$ (Fig. 7 (b)-right side), the site fraction of $\mathrm{Co}^{2+}$ ions shows a gradual decreasing tendency from the low $\mathrm{PO}_{2}$ side to the high oxygen potential side, whereas $\mathrm{Co}^{4+}$ changes in the opposite direction. The site fraction of $\mathrm{Co}^{3+}$ goes through a broad maximum near the central part of the membrane. The distribution of Co cations is in line with the fast redox reactions taking place inside the oxide, as described in Section 2.2.1. With increasing oxygen partial pressure, $\mathrm{Co}^{2+}$ changes into $\mathrm{Co}^{4+}$ and $\mathrm{Co}^{3+}$; meanwhile, $\mathrm{Co}^{3+}$ changes into $\mathrm{Co}^{2+}$ and $\mathrm{Co}^{4+}$ through charge disproportionation. At the later stage of simulation, from $\mathrm{t}=5184000 \mathrm{~s}$ to $\mathrm{t}=31000000 \mathrm{~s}$ ( 1 year) (Fig. 7 (a)-left side), the site fraction profiles are nearly in superposition. The site fraction profile of $\mathrm{La}^{3+}$ in the perovskite phase does not vary with the oxygen potential gradient over time, maintaining a value of 1 because the mass transport of $\mathrm{La}$ (variation of $x(\mathrm{La})$ ) is through the local equilibrium phase transformation from perovskite to $\mathrm{La}_{2} \mathrm{O}_{3}$ instead of changing the site fraction of $\mathrm{La}^{3+}$ in the single-phase perovskite, due to the very limited A- to B-site non-stoichiometry supported in the perovskite phase. Fig. 7 shows the variation of oxygen non-stoichiometry $\delta$ in $\mathrm{LaCoO}_{3-\delta}$, which decreases with increasing oxygen partial pressure and approaches zero at the high $\mathrm{PO}_{2}$ side.
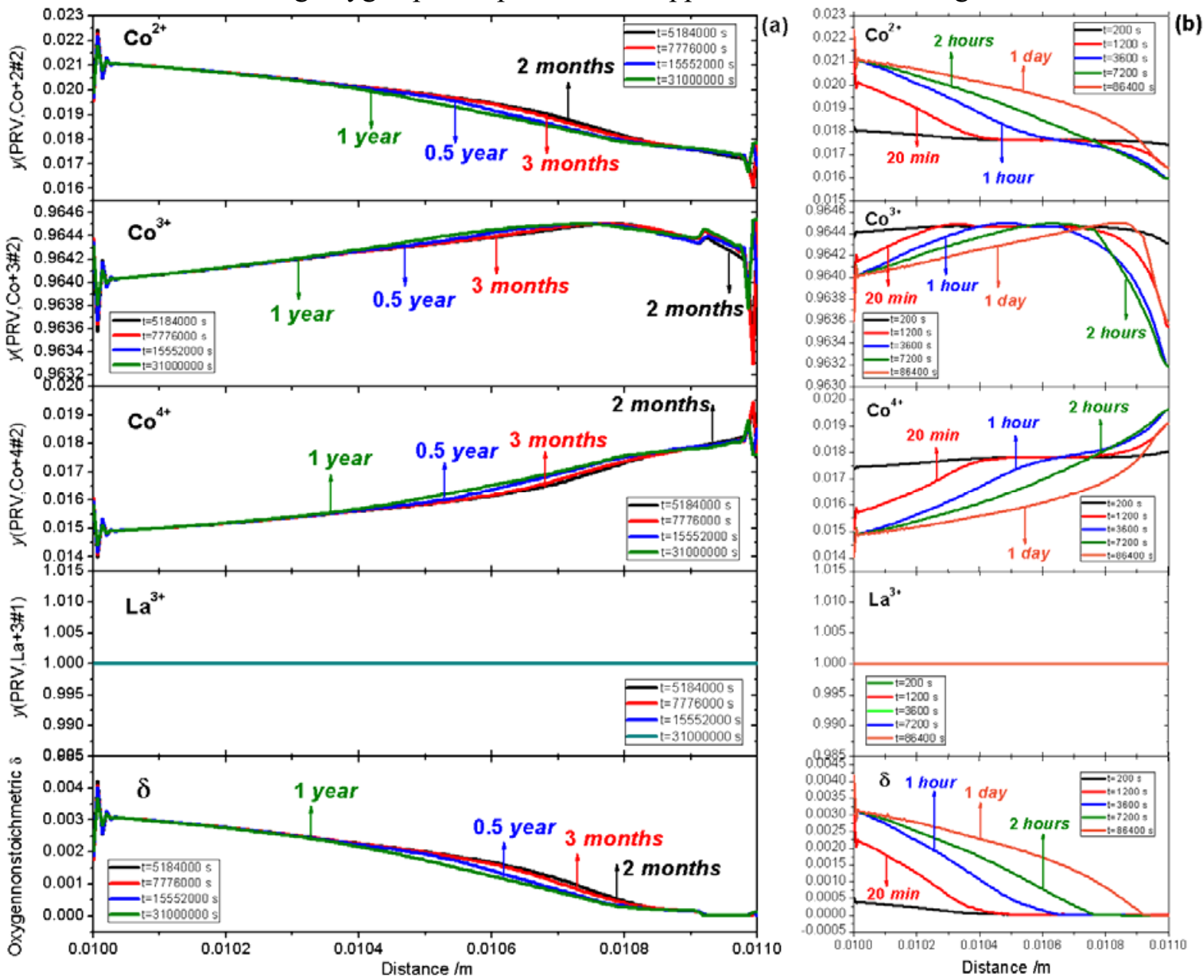

Fig. 7. Model-predicted ion site fraction profiles of $\mathrm{Co}^{2+}, \mathrm{Co}^{3+}, \mathrm{Co}^{4+}, \mathrm{La}^{3+}$ and Oxygen non-stoichiometric $\delta$ versus distance at $1073 \mathrm{~K}$ from $\mathrm{t}=200 \mathrm{~s}$ to $\mathrm{t}=31000000 \mathrm{~s}$ (1 year): (a)-Left: $\mathrm{t}=5184000 \mathrm{~s}$ to $\mathrm{t}=31000000 \mathrm{~s}$. (b)-Right: $\mathrm{t}=200 \mathrm{~s}$ to $\mathrm{t}=86400 \mathrm{~s}$. 


\subsection{Formation of new phases}

On the basis of the preceding analysis of the demixing profiles, the formation of new phases is predicted. According to the phase diagram in Fig. 2, at oxygen partial pressures of $1 \times 10^{-4}$ bar to 0.21 bar, the possible new phases include $\mathrm{Co}_{3} \mathrm{O}_{4}, \mathrm{CoO}$, gaseous $\mathrm{O}_{2}$ and $\mathrm{La}_{2} \mathrm{O}_{3}$. Fig. 8 presents the variation of different phase fractions across the entire membrane during the demixing process at $1073 \mathrm{~K}$ from $\mathrm{t}=0 \mathrm{~s}$ to $\mathrm{t}=31000000 \mathrm{~s}$ (i.e., 1 year). As shown in Fig. 8(a-c), accompanying the diffusion of the cations, the region of new phases $\left(\mathrm{Co}_{3} \mathrm{O}_{4}\right.$ and $\left.\mathrm{La}_{2} \mathrm{O}_{3}\right)$ expands gradually, resulting in the partial decomposition of the $\mathrm{LaCoO}_{3-\delta}$ perovskite over the entire region, especially at the high $\mathrm{PO}_{2}$ side. The $\mathrm{Co}_{3} \mathrm{O}_{4}$ phase expands towards the center part at the beginning and then withdraws towards the high $\mathrm{PO}_{2}$ side from $\mathrm{t}=7200 \mathrm{~s}(2 \mathrm{~h})$, whereas its phase fraction keeps increasing at the high $\mathrm{PO}_{2}$ side. The amount of $\mathrm{Co}_{3} \mathrm{O}_{4}$ phase achieves $3 \%$ at the primary surface of the membrane that is exposed to high $\mathrm{PO}_{2}$ atmosphere after 1 year and continues to increase. The phase fraction of $\mathrm{La}_{2} \mathrm{O}_{3}$ is approximately $0.01000 \%$ at the low $\mathrm{PO}_{2}$ side and remains at a higher value of approximately $0.05000 \%$ in the central part near the $\mathrm{Co}_{3} \mathrm{O}_{4}$ phase region after 1 year, i.e., $\mathrm{La}_{2} \mathrm{O}_{3}$ forms predominantly near the center-high $\mathrm{PO}_{2}$ part of the membrane instead of at the low $\mathrm{PO}_{2}$ side, which as already discussed is associated with the formation of $\mathrm{Co}_{3} \mathrm{O}_{4}$ phase on the high $\mathrm{PO}_{2}$ side resulting in the depletion of Co, accordingly enrichment of La ions locally. The formation of $\mathrm{La}_{2} \mathrm{O}_{3}$ near $x=0.011 \mathrm{~m}$ at 2 and 3 months is likely due to numerical, instabilities which may be the source of some uncertainty/artifacts in the calculations, resulting from the unavoidable compromise between overall accuracy and computational time. The above phase decomposition phenomenon corresponds to the experimental observations in Refs. [1-5], where only blocky-shaped cobalt oxide, and not lanthanum oxide (Note: It might be not enough to be detected) was detected on the oxidizing side. $\mathrm{CoO}$ appears to form at $\mathrm{x}=0.011 \mathrm{~m}$ after $t=2400000 \mathrm{~s}$ ( 1 month). This is associated with a sudden drop of the $\mathrm{PO}_{2}$ at the feed side of the membrane, the origin of which is likely also related to numerical instabilities.

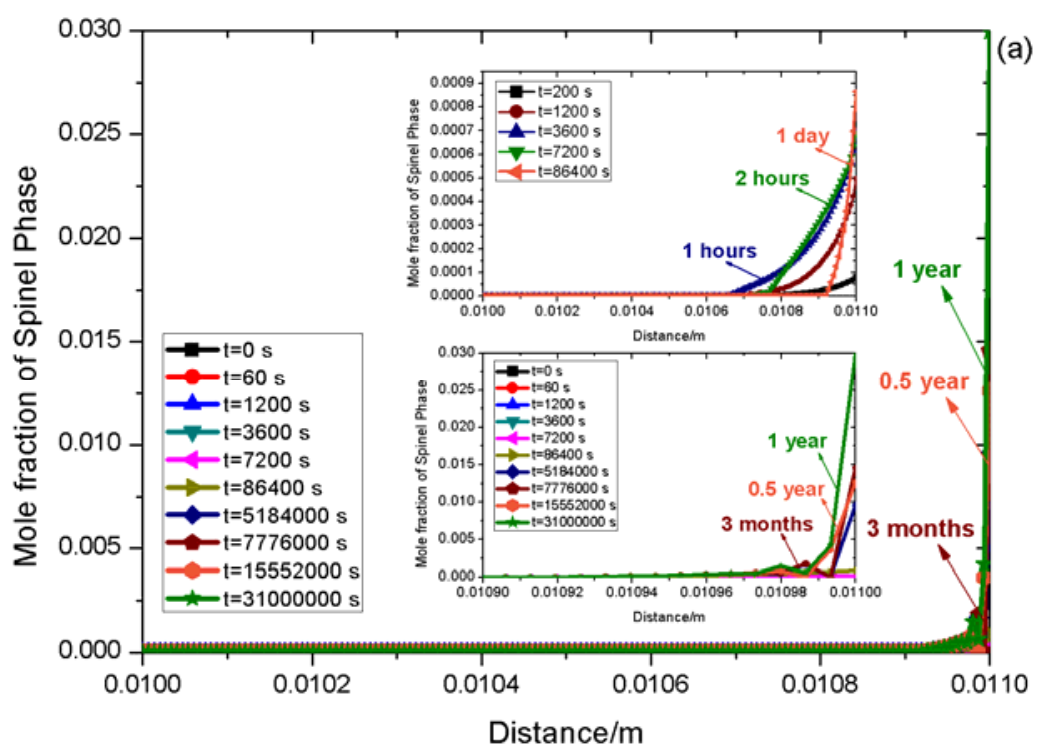




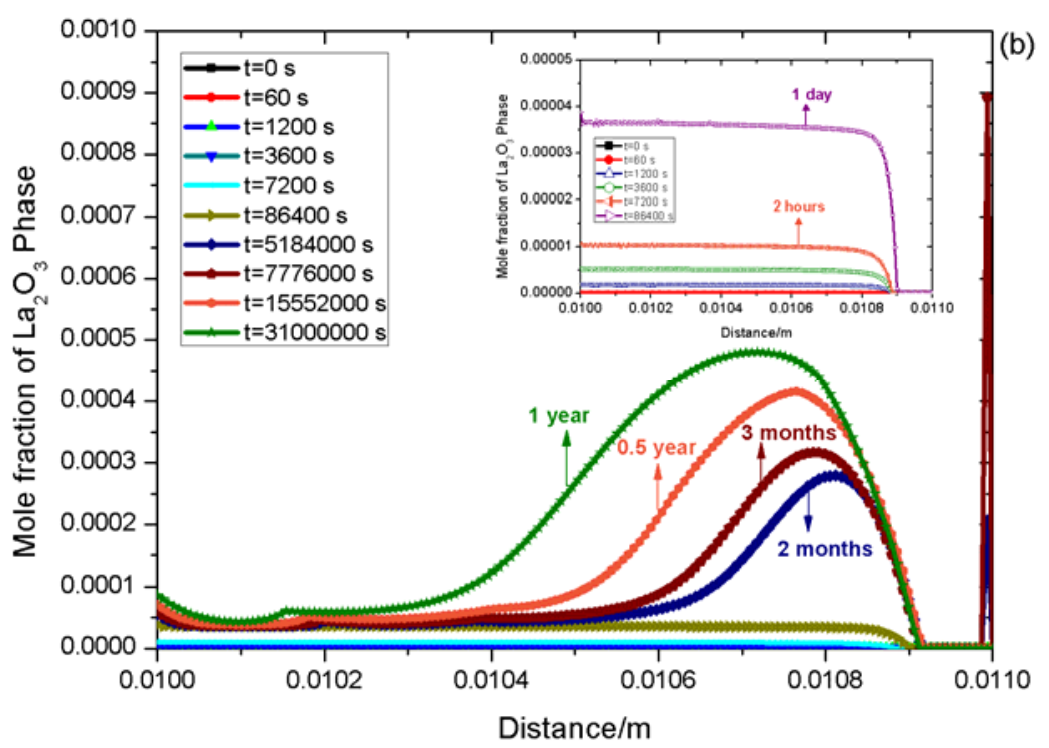

449

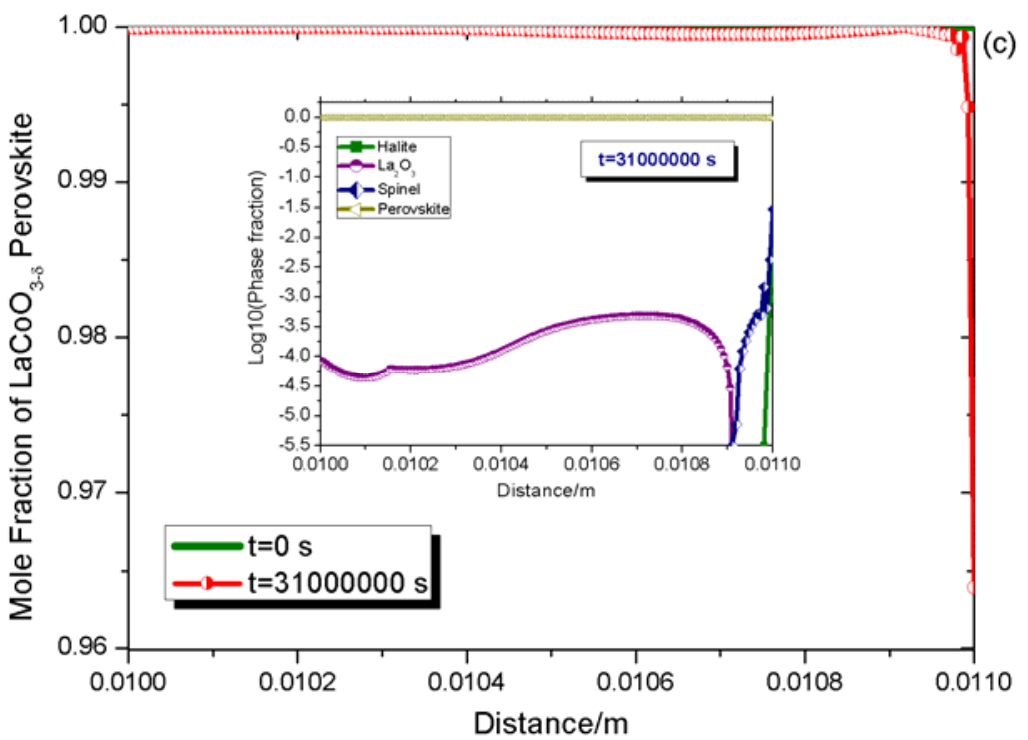

Fig. 8. Variation of different phase fractions across the entire membrane at $1073 \mathrm{~K}$ from $t=0 \mathrm{~s}$ to $t=31000000 \mathrm{~s}$ (1 year). (a) Phase fraction of $\mathrm{Co}_{3} \mathrm{O}_{4}$, (b) Phase fraction of $\mathrm{La}_{2} \mathrm{O}_{3}$, and (c) Phase fraction of $\mathrm{LaCoO}_{3-\delta}$ and logarithmic graph of all phases at $t=31000000 \mathrm{~s}$ (1 year).

\subsection{Diffusion path during kinetic demixing and decomposition}

Diffusion path is an effective means of representing the relationship between the kinetic and thermodynamic aspects of a system, which can clearly describe the integrated evolution of the thermodynamic and kinetic behavior. The diffusion path of the kinetic decomposition process in the $\mathrm{LaCoO}_{3-\delta}$ oxide membrane at $1073 \mathrm{~K}$ from $t=0 \mathrm{~s}$ to $31000000 \mathrm{~s}$ (1 year) is shown in Fig. 9. The diffusion path shows a special variation feature, which starts with an initial homogenous composition point at $t=0 \mathrm{~s}$ (black point 1); then, demixing into a heterogeneous composition occurs across the entire region. As shown in Fig. 9, the diffusion path becomes longer over time, i.e., the composition range increases and diverges gradually, and the composition on both sides enters into multiphase region after $t=60 \mathrm{~s}$, suggesting the occurrence of phase transformation induced by kinetic decomposition in the original single $\mathrm{LaCoO}_{3-\delta}$ oxide phase. The perovskite phase decomposes into two phases of $\mathrm{La}_{2} \mathrm{O}_{3}+$ perovskite on the low $\mathrm{PO}_{2}$ side, whereas on the high $\mathrm{PO}_{2}$ 
side, the original perovskite phase decomposes into $\mathrm{Co}_{3} \mathrm{O}_{4}+$ perovskite $+\mathrm{O}_{2}$ gas phases. Therefore, the $\mathrm{O}_{2}$ gas phase forms during the kinetic decomposition process. After $t=2400000 \mathrm{~s}$ ( 1 month), the $\mathrm{CoO}$ phase appears at the high $\mathrm{PO}_{2}$ side. Following the diffusion path at different time steps, the phase transformation and concentration variation inside the oxide membrane during the kinetic demixing and decomposition process can be clearly observed.
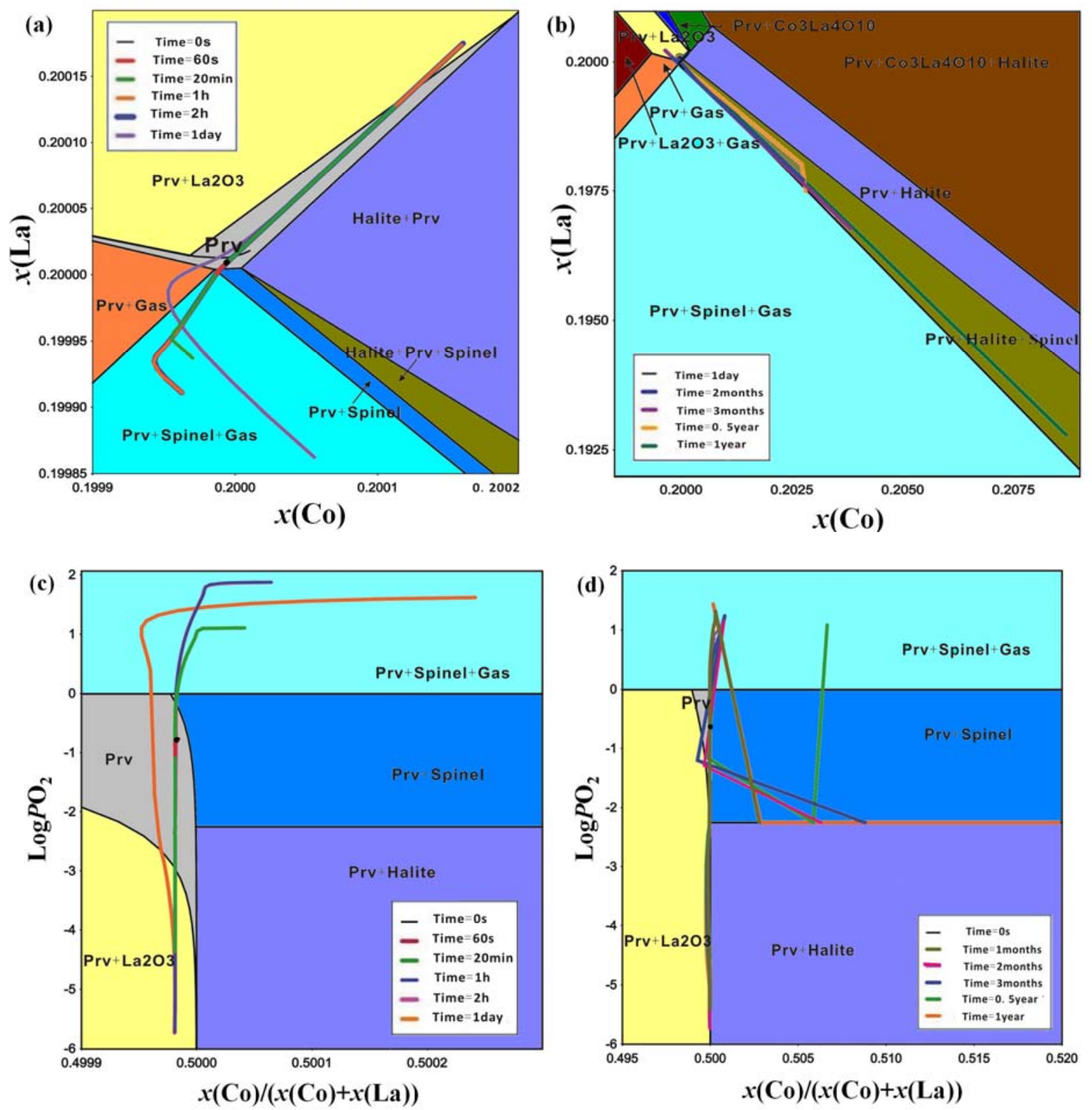

Fig. 9. Diffusion paths of the kinetic demixing process in $\mathrm{LaCoO}_{3-\delta}$ oxide at $1073 \mathrm{~K}$ (a) at $\mathrm{t}=0 \mathrm{~s}, 60 \mathrm{~s}, 1200 \mathrm{~s}$, $7200 \mathrm{~s}, 36000 \mathrm{~s}$, and $86400 \mathrm{~s}$ in the isothermal $x(\mathrm{La})-x(\mathrm{Co})$ phase diagram, (b) at $\mathrm{t}=5184000 \mathrm{~s}, 7776000 \mathrm{~s}$, $15552000 \mathrm{~s}(0.5 \mathrm{year})$, and $31000000 \mathrm{~s}$ (1 year) in the isothermal $x(\mathrm{La})-x(\mathrm{Co})$ phase diagram, (c) at $\mathrm{t}=0 \mathrm{~s}, 60 \mathrm{~s}$, $1200 \mathrm{~s}, 7200 \mathrm{~s}, 36000 \mathrm{~s}$, and $86400 \mathrm{~s}$ in the isothermal $P \mathrm{O}_{2}$-composition phase diagram, and (d) at $\mathrm{t}=2400000 \mathrm{~s}$, $5184000 \mathrm{~s}, 7776000 \mathrm{~s}, 15552000 \mathrm{~s}$ ( 0.5 year), and $31000000 \mathrm{~s}$ (1 year) in the isothermal $P \mathrm{O}_{2}$-composition phase diagram. 


\section{Conclusions}

On the basis of the experimental diffusivities, the composition and temperature-dependent diffusion mobilities database in the $\mathrm{LaCoO}_{3-\delta}$ phase was developed, from which a quantitative description of the kinetic demixing and decomposition process in $\mathrm{LaCoO}_{3-\delta}$ oxygen membranes under an oxygen potential gradient during the long-term service lifetime (i.e., almost 1 year) was realized with the aid of the available thermodynamic database. The effects of the kinetic demixing and decomposition process on the degradation of the membrane are the following,

- Enrichment of the faster cations at the high $P_{2}$ side and the slower cations at the low $P \mathrm{O}_{2}$ side is observed, which results in the formation of new oxide phases across the membrane. The amount of $\mathrm{Co}_{3} \mathrm{O}_{4}$ phase on the primary surface increases with increasing time.

- The kinetic demixing rate in the mixed conducting $\mathrm{ABO}_{3}$-type phase can be divided into two stages: the first fast stage is the establishment of the oxygen potential gradient, which is controlled by the mobility of oxygen ions rather than that of Co or La ions; the second slow stage is the demixing of cations and the formation of new phases, of which the rate is determined by the mobility of $\mathrm{Co}$ ions rather than La ions in $\mathrm{ABO}_{3}$-type perovskite due to its structural defect characteristics.

- The present methods for studying the kinetic decomposition in the $\mathrm{ABO}_{3}$-type perovskite phase can be extended to multicomponent systems $\mathrm{A}_{1-\mathrm{x}} \mathrm{C}_{\mathrm{x}} \mathrm{B}_{1-\mathrm{y}} \mathrm{D}_{\mathrm{y}} \mathrm{O}_{3-\delta}$, so a complete comparison to the experimental information may be performed.

\section{Acknowledgments}

The authors gratefully acknowledge the research funding provided by the Danish Council for Strategic Research/Innovationsfonden for the Sino-Danish Strategic Research Collaboration within Renewable Energy project no. 11-116387 "ENEFOX - Energy efficient oxygen production for a sustainable energy system". Lijun Zhang acknowledges the project supported by State Key Laboratory of Powder Metallurgy Foundation, Central South University, Changsha, China. The authors also thank Prof. J. Ågren (KTH) for fruitful discussions and advices.

\section{Appendix A. Verification based on electrochemistry theory}

The diffusion flux of the ions based on Onsager's theory without considering cross-effects in the lattice-fixed reference fame is as follows:

$$
\begin{aligned}
& \vec{J}_{i}=-L_{i i} \nabla \eta_{i}=-\frac{M_{i}^{*} x_{i}}{V_{m}}\left(\nabla \mu_{i}+z_{i} F \nabla \varphi\right) \\
& \left(i=\mathrm{La}^{3+}, \mathrm{Co}^{2+}, \mathrm{Co}^{3+}, \mathrm{Co}^{4+}, \mathrm{O}^{2-}\right)
\end{aligned}
$$

1) The local equilibrium assumption is introduced in the oxide:

$$
0.5 O_{2}+2 e \rightarrow O^{2-} \quad 0.5 \nabla \mu_{O_{2}}+2 \nabla \mu_{e}=\nabla \mu_{O^{2-}}
$$

2) Due to the electroneutrality conditions, the total electric current density equals zero:

$$
\begin{aligned}
& \sum_{i}^{n} \vec{I}_{i}=\sum_{i}^{n} n_{i} q_{i} v_{i}=F \sum_{i}^{n} z_{i} \vec{J}_{i}=0,\left(i=\mathrm{La}^{3+}, \mathrm{Co}^{2+}, \mathrm{Co}^{3+}, \mathrm{Co}^{4+}, \mathrm{O}^{2-}\right) \\
& \vec{I}_{\mathrm{La}^{3+}}+\vec{I}_{\mathrm{Co}^{2+}}+\vec{I}_{\mathrm{Co}^{3+}}+\vec{I}_{\mathrm{Co}^{4+}}+\vec{I}_{\mathrm{O}^{2-}}+\vec{I}_{e}=0
\end{aligned}
$$


Because the motion of cations is much slower than that of electrons and oxygen anions,

The following simplification can be reasonably made,

$\vec{I}_{O^{2-}}=-\vec{I}_{e} \Leftrightarrow-\frac{\sigma_{O^{2-}}}{-2 F} \nabla \eta_{O^{2-}}=\frac{\sigma_{e}}{-F} \nabla \eta_{e} \Leftrightarrow \nabla \eta_{O^{2-}}=\frac{-2 \sigma_{e}}{\sigma_{O^{2-}}} \nabla \eta_{e}$

$\nabla \mu_{O^{2-}}-2 F \nabla \varphi=\frac{-2 \sigma_{e}}{\sigma_{O^{2-}}}\left(\nabla \mu_{e}-F \nabla \varphi\right)$

Then, by substituting Eq. (A.2) into Eq. (A.5), the electric potential gradient can be obtained,

$$
\nabla \varphi=\frac{1}{2 F}\left(\nabla \mu_{O^{2-}}-\nabla \eta_{O^{2-}}\right)=\frac{1}{2 F}\left(\nabla \mu_{O^{2-}}-\frac{\sigma_{e}}{2\left(\sigma_{O^{2-}}+\sigma_{e}\right)} \nabla \mu_{O_{2}}\right)
$$

By substituting Eq. (A.6) into Eq. (A.1), the corresponding diffusion flux becomes:

$$
\vec{J}_{i}=-\frac{M_{i}^{*} x_{i}}{V_{m}}\left(\nabla \mu_{i}+z_{i} \cdot \frac{1}{2}\left(\nabla \mu_{O^{2-}}-\frac{\sigma_{e}}{2\left(\sigma_{O^{2-}}+\sigma_{e}\right)} \nabla \mu_{O_{2}}\right)\right)
$$

Considering that $\mathrm{LaCoO}_{3}-\delta$ oxide is an electronic conductor, in which the electron transfer needed to maintain a zero charge flux (charge balance) is much faster than the diffusion jumps, i.e., $\sigma_{O^{-2}}<<\sigma_{e}$, Eq. (A.7) can be simplified to,

$$
\vec{J}_{i}=-\frac{M_{i}^{*} x_{i}}{V_{m}}\left(\nabla \mu_{i}+z_{i} \cdot \frac{1}{2}\left(\nabla \mu_{O^{2-}}-\frac{1}{2} \nabla \mu_{O_{2}}\right)\right)
$$

Furthermore, the approximation $\nabla \mu_{O^{2-}} \approx \nabla \mu_{O}, \quad \nabla \mu_{O_{2}} \approx 2 \nabla \mu_{O}$ (Assume equilibrium at interface

$\mathrm{O}+\mathrm{O} \Leftrightarrow \mathrm{O}_{2}$ ) can be used, which is only valid in the electronic conductor where the change in the chemical potential of the electrons is much smaller than that in the chemical potential of oxygen. Thus Eq. (A.8) can be reasonably simplified as follows,

$$
\vec{J}_{i}=-\frac{M_{i}^{*} x_{i}}{V_{m}} \nabla \mu_{i}
$$

\section{Appendix B. Derivation of diffusion equations in $\mathrm{LaCoO}_{3-\delta}$ single phase}

Based on the previous thermodynamic sublattice model: $\left(\mathrm{La}^{3+}, \mathrm{Va}(\mathrm{La})\right)_{1}\left(\mathrm{Co}^{2+}, \mathrm{Co}^{3+}, \mathrm{Co}^{4+}, \mathrm{Va}(\mathrm{Co})\right)_{1}$ $\left(\mathrm{O}^{2-}, \mathrm{Va}(\mathrm{O})\right)_{3}$, the Gibbs-Duhem equation in a thermodynamic system at constant temperature and pressure should be satisfied, which controls the internal mass transport process:

$$
x_{L a} \nabla \mu_{L a}+x_{C o} \nabla \mu_{C o}+x_{O} \nabla \mu_{O}=0 \quad x_{L a}+x_{C o}+x_{O}=1
$$

For the perovskite phase the vacancy-exchange mechanism of diffusion is predominant. i.e., diffusion occurs by atoms jumping into neighboring vacant lattice sites. From absolute reaction rate theory, and by assuming that the vacancy concentration is governed by thermodynamic equilibrium, the diffusion flux of $\mathrm{La}^{3+}$, Co ions and $\mathrm{O}^{2-}$ can be expressed along the direction of $z$ in a lattice-fixed reference frame $[17,18]$, 
$\vec{J}_{L a}=-\left(x_{L a} y_{V a}^{1} M_{L a V a}^{1}\right) \frac{1}{V_{m}} \nabla \mu_{L a}=-\left(x_{L a} y_{V a}^{1} M_{L a V a}^{1}\right) \frac{1}{V_{m}}\left(\frac{\partial \mu_{L a}}{\partial x_{L a}} \frac{\partial x_{L a}}{\partial z}+\frac{\partial \mu_{L a}}{\partial x_{C o}} \frac{\partial x_{C o}}{\partial z}+\frac{\partial \mu_{L a}}{\partial x_{O}} \frac{\partial x_{O}}{\partial z}\right)$

$\vec{J}_{C o}=-\left(x_{C o} y_{V a}^{2} M_{C o V a}^{2}\right) \frac{1}{V_{m}} \nabla \mu_{C o}$

548

$$
=-\left(x_{C o} y_{V a}^{2} M_{C o V a}^{2}\right) \frac{1}{V_{m}}\left(\frac{\partial \mu_{C o}}{\partial x_{L a}} \frac{\partial x_{L a}}{\partial z}+\frac{\partial \mu_{C o}}{\partial x_{C o}} \frac{\partial x_{C o}}{\partial z}+\frac{\partial \mu_{C o}}{\partial x_{O}} \frac{\partial x_{O}}{\partial z}\right)
$$

$$
\vec{J}_{O}=-\left(x_{O} y_{V a}^{3} M_{\text {OVa }}^{3}\right) \frac{1}{V_{m}} \nabla \mu_{O}=-\left(x_{O} y_{V a}^{3} M_{\text {OVa }}^{3}\right) \frac{1}{V_{m}}\left(\frac{\partial \mu_{O}}{\partial x_{L a}} \frac{\partial x_{L a}}{\partial z}+\frac{\partial \mu_{O}}{\partial x_{C o}} \frac{\partial x_{C o}}{\partial z}+\frac{\partial \mu_{O}}{\partial x_{O}} \frac{\partial x_{O}}{\partial z}\right)
$$

550

551

552

$$
\begin{aligned}
\vec{J}_{C o} & =-\left(x_{C o} y_{V a}^{2} M_{C o V a}^{2}\right) \frac{1}{V_{m}} \nabla \mu_{C o} \\
& =-\left(x_{C o} y_{V a}^{2} M_{C o V a}^{2}\right) \frac{1}{V_{m}}\left(\left(\frac{\partial \mu_{C o}}{\partial x_{L a}}-\frac{\partial \mu_{C o}}{\partial x_{O}}\right) \frac{\partial x_{L a}}{\partial z}+\left(\frac{\partial \mu_{C o}}{\partial x_{C o}}-\frac{\partial \mu_{C o}}{\partial x_{O}}\right) \frac{\partial x_{C o}}{\partial z}\right)
\end{aligned}
$$

$$
\vec{J}_{O}=-\left(x_{O} y_{V a}^{3} M_{\text {OVa }}^{3}\right) \frac{1}{V_{m}} \nabla \mu_{O}=-\left(x_{O} y_{V a}^{3} M_{O V a}^{3}\right) \frac{1}{V_{m}}\left(\left(\frac{\partial \mu_{O}}{\partial x_{L a}}-\frac{\partial \mu_{O}}{\partial x_{O}}\right) \frac{\partial x_{L a}}{\partial z}+\left(\frac{\partial \mu_{O}}{\partial x_{C o}}-\frac{\partial \mu_{O}}{\partial x_{O}}\right) \frac{\partial x_{C o}}{\partial z}\right)
$$




\section{References}

[1] D. Schlehuber, E. Wessel, L. Singheiser, T. Markus. Long-term operation of a $\mathrm{La}_{0.58} \mathrm{Sr}_{0.4} \mathrm{Co}_{0.2} \mathrm{Fe}_{0.8} \mathrm{O}_{3-\delta}$ membrane for oxygen separation, J. Membrane Sci., 351 (2010) 16-20.

[2] R.H.E. van Doorn, H.J.M. Bouwmeester, A.J. Burggraaf, Kinetic decomposition of $\mathrm{La}_{0.3} \mathrm{Sr}_{0.7} \mathrm{CoO}_{3-\delta}$ perovskite membranes during oxygen permeation, Solid State Ionics, 111 (1998) 263-272.

[3] H.L. Lein, K. Wiik, T. Grande, Kinetic demixing and decomposition of oxygen permeable membranes, Solid State Ionics 177 (2006) 1587-1590.

[4] B. Wang, B. Zydorczak, Z.T. Wu, K. Li, Stabilities of $\mathrm{La}_{0.6} \mathrm{Sr}_{0.4} \mathrm{Co}_{0.2} \mathrm{Fe}_{0.8} \mathrm{O}_{3-\delta}$ oxygen separation membranes-Effects of kinetic demixing/decomposition and impurity segregation. J. Membrane Sci., 344 (2009) 101-106.

[5] B. Wang, B. Zydorczak, D. Poulidi, L.S. Metcalfe, K. Li, A further investigation of the kinetic demixing/decomposition of $\mathrm{La}_{0.6} \mathrm{Sr}_{0.4} \mathrm{Co}_{0.2} \mathrm{Fe}_{0.8} \mathrm{O}_{3-\delta}$ oxygen separation membranes. J. Membrane Sci., 369 (2011) 526-535.

[6] M. Martin , Electrotransport and demixing in oxides, Solid State Ionics ,136-137 (2000) 331-337.

[7] M. Martin, Materials in thermodynamic potential gradients, J.Chem.Thermodynamics, 35 (2003) 1291-1308.

[8] J.-O. Hong, O. Teller, M. Martin , H.-I. Yoo, Demixing of mixed oxide (A,B)O in an oxygen potential gradient:a numerical solution of the time evolution of the demixing process, Solid State Ionics, 123 (1999) 75-85.

[9] T. Tshikawa, H. Sato, R. Kikuchi, S.A. Akbar, Demixing of materials under chemical potential gradients, J. Am. Cer. Soc., 68(1) (1985) 1-6.

[10] T. Ishikawa, S.A. Akbar, W. Zhu, H. Sato, Time evolution of demixing in oxides under an oxygen potential gradient, J. Am. Cer. Soc., 71(7) (1988) 513-521.

[11] C. Chatzichristodoulou, M. Chen, P.V. Hendriksen, T. Jacobsen, M.B. Mogensen, Understanding degradation of solid oxide electrolysis cells through modeling of electrochemical potential profiles, Electrochimica Acta, 189 (2016) 265-282.

[12] H. Schmalzried, W. Laqua, P.L. Lin, Crystalline oxide solid solutions in oxygen potential gradients, Z.Naturforsch., 34(2) (1979) 192-199.

[13] S. McIntosh, S.B. Adler, J.M. Vohs, Effect of polarization on and implications for characterization of LSM-YSZ composite cathodes. Electrochem. Solid St., 7(5) (2004) 111-114.

[14] A. Jun, J. Kim, J. Shin, Perovskite as a cathode material: a review of its role in solid-oxide fuel cell technology. Chem. Electro. Chem. , 3 (4) (2016).

[15] J. Richter, P. Holtappels, T. Graule, Materials design for perovskite SOFC cathodes. Monatshefte für 
Chemie-Chemical Monthly. 140(9) (2009) 985-999.

[16] S. Hallström, M. Halvarsson, L. Höglund, et al. High temperature oxidation of chromium: Kinetic modeling and microstructural investigation. Solid State Ionics, 240 (2013) 41-50.

[17] J. Ågren, Diffusion in phases with several components and sublattices. Acta Mater., 43 (1982) 421-430.

[18] J.O. Andersson, J. Ågren, Models for numerical treatment of multicomponent diffusion in simple phases. J. Appl. Phys. 72 (1992) 1350-1355.

[19] L.J. Zhang, Q. Chen, Revisiting the phenomenological model for effect of chemical ordering on diffusion, Intermetallics, 70 (2016) 72-81.

[20] L.J. Zhang, Y. Du, I. Steinbach, Q. Chen, B.Y. Huang, Diffusivities of an Al-Fe-Ni melt and their effects on the microstructure during solidification, Acta Mater., 58 (2010) 3664-3675.

[21] S. Hallström, L. Höglund, J. Ågren, Modeling of iron diffusion in the iron oxides magnetite and hematite with variable stoichiometry, Acta Mater., 59 (2011) 53-60.

[22] W. Zhang, M. Chen, P.V. Hendriksen, Investigation of Degradation Mechanisms of LSCF Based SOFC Cathodes - by CALPHAD Modeling and Experiments, Ph. D thesis, Technical University of Denmark, 2013. http://orbit.dtu.dk/en/publications/investigation-of-degradation-mechanisms-of-lscf-based-sofc-cathodes--by-calp had-modeling-and-experiments(150cc8b2-ccc1-4803-b5c9-feb4d202fc61).html

[23] M. Yang, Y. Zhong, Z.K. Liu, Defect analysis and thermodynamic modeling of $\mathrm{LaCoO}_{3-\delta}$, Solid State Ionics, 178 (2007) 1027-1032.

[24] S. Darvish, Y. Zhong, S. Gopalan, Thermodynamic Stability of $\mathrm{La}_{0.6} \mathrm{Sr}_{0.4} \mathrm{Co}_{0.2} \mathrm{Fe}_{0.8} \mathrm{O}_{3-\delta}$ in Carbon Dioxide Impurity: A Comprehensive Experimental and Computational Assessment., ECS Transactions, 78 (2017) 1021-1025.

[25] C.C. Wang, S. He, K. Chen, M.R. Rowles, S. Darvish, Y. Zhong, S.P. Jiang, Effect of $\mathrm{SO}_{2}$ Poisoning on the Electrochemical Activity of $\mathrm{La}_{0.6} \mathrm{Sr}_{0.4} \mathrm{Co}_{0.2} \mathrm{Fe}_{0.8} \mathrm{O}_{3-\delta}$ Cathodes of Solid Oxide Fuel Cells, J. Electrochem. Soc., 164 (2017) F514-F524.

[26] Z. Lu, S. Darvish, J. Hardy, J. Templeton, J. Stevenson, Y. Zhong, $\mathrm{SrZrO}_{3}$ Formation at the Interlayer/Electrolyte Interface during $\left(\mathrm{La}_{1-\mathrm{x}} \mathrm{Sr}_{\mathrm{x}}\right)_{1-\delta} \mathrm{Co}_{1-\mathrm{y}} \mathrm{Fe}_{\mathrm{y}} \mathrm{O}_{3}$ Cathode Sintering, J. Electrochem. Soc., 164 (2017), F3097-F3103.

[27] S. Darvish, S. Gopalan, Y. Zhong, Thermodynamic stability maps for the $\mathrm{La}_{0.6} \mathrm{Sr}_{0.4} \mathrm{Co}_{0.2} \mathrm{Fe}_{0.8} \mathrm{O}_{3 \pm \delta}-\mathrm{CO}_{2}-\mathrm{O}_{2}$ system for application in solid oxide fuel cells, J. Power Sources, 336 (2016) 351-359.

[28] S. Darvish, M. Asadikiya, B. Hu, P. Singh, Y, Zhong. Thermodynamic prediction of the effect of $\mathrm{CO}_{2}$ to the stability of ( $\left.\mathrm{La}_{0.8} \mathrm{Sr}_{0.2}\right){ }_{0.98} \mathrm{MnO}_{3 \pm \delta}$, system. Int. J. Hydrogen Energ., 41(24) (2016)10239-10248.

[29] J.B. Brady, Reference frames and diffusion coefficients, Am. J. Sci., 275 (1975) 954-983. 
[30] J. Ågren, Binary and Multicomponent Diffusion. John Wiley \& Sons, Inc. (2002).

[31] H. Larsson, A. Engström, A homogenization approach to diffusion simulations applied to $\alpha+\gamma \mathrm{Fe}-\mathrm{Cr}-\mathrm{Ni}$ diffusion couples, Acta Mater., 54 (2006) 2431-2439.

[32] H. Larsson, H. Strandlund, M. Hillert, Unified treatment of Kirkendall shift and migration of phase interfaces. Acta Mater., 54 (2006) 945-951.

[33] Wiener O H. Die theorie des mischkörpers für das feld der stationären strömung. 1. abhandlung: Die mittelwertsätze für kraft, polarisation und energie. BG Teubner, 1912.

[34] A. Borgenstam, A. Engström, L. Höglund, J. Ågren, DICTRA, a tool for simulation of diffusional transformations in alloys, J. Phase Equilibr., 21 (2000) 269-280.

[35] T. Ishigaki, S. Yamauchi, J. Mizusaki, K. Fueki, Tracer Diffusion Coefficient of Oxide Ions in $\mathrm{LaCoO}_{3-\delta}$ Single Crystal. J. Solid. State Chem., 54 (1984) 100-107.

[36] C.H. Chen, H. Kruidhof, H. J. M. Bouwmeester, A.J. Burggraaf. Ionic conductivity of perovskite LaCoO3 measured by oxygen permeation technique. J. Appl. Electrochem., 27 (1997) 71-75.

[37] D.S. Tsvetkov, A. I. Vylkov, A.Yu. Zuev, and A.N. Petrov, The Diffusion of Oxygen and Ion Transport in Lanthanum Cobaltite $\mathrm{LaCoO}_{3-\delta}$., Russ. J. Phys. Chem. A, 82 (2006) 855-859.

[38] B. J. Yan, J.Y. Zhang and J.H. Liu, Kinetic Studies of $\mathrm{LaCoO}_{3-\delta}$ Preparation from Solid State Reactions. High. Temp. Mat. PR-ISR , 23 (2004) 163-175.

[39] M. Palcut, K. Wiik, T. Grande, Cation Self-Diffusion in $\mathrm{LaCoO}_{3}$ and $\mathrm{La}_{2} \mathrm{CoO}_{4}$ Studied by Diffusion Couple Experiments. J. Phys. Chem. B, 111 (2007) 2299-2308.

[40] M. Palcut, R. Knibbe, K. Wiik, T. Grande, Cation inter-diffusion between $\mathrm{LaMnO}_{3}$ and $\mathrm{LaCoO}_{3}$ materials, Russ., Solid State Ionics., 202 (2011) 6-13.

[41] M. Palcut, J.S. Christensen, K. Wiik, T. Grande, Impurity diffusion of ${ }^{141} \mathrm{Pr}$ in $\mathrm{LaMnO}_{3}, \mathrm{LaCoO}_{3}$ and $\mathrm{LaFeO}_{3}$ materials, Phys. Chem. Chem. Phys., 10 (2008) 6544-6552. 